\title{
Coordinatively unsaturated sites in zeolite matrix: Construction and catalysis
}

\author{
Weijie Li a, Lanan Sun a, Linjun Xie a , Xin Deng a Naijia Guan a,b, Landong Li a,b,* \\ a School of Materials Science and Engineering \& National Institute for Advanced Materials, Nankai University, Tianjin 300350, China \\ ${ }^{\mathrm{b}}$ Key Laboratory of Advanced Energy Materials Chemistry of Ministry of Education, Nankai University, Tianjin 300071, China
}

\section{A R T I C L E I N F O}

\section{Article history:}

Received 21 March 2019

Accepted 14 April 2019

Published 5 September 2019

\section{Keywords:}

Coordinatively unsaturated sites

Zeolite matrix

Construction

Characterization

Catalysis

\begin{abstract}
A B S T R A C T
Zeolites with ordered porous structure of molecular size are widely employed as commercial adsorbents and catalysts. On the other hand, the zeolite matrix is regarded as an ideal scaffold for hosting coordinatively unsaturated sites. Remarkable achievements have been made dealing with the construction, characterization and catalytic applications of coordinatively unsaturated sites in zeolite matrix. Herein, a literature overview of recent progresses on this important topic is presented from the specific view of coordination chemistry. Different strategies to construction coordinatively unsaturated sites in zeolite matrix, in zeolite framework or extraframework positions, are first introduced and their characteristics are compared. Then, spectroscopic techniques to determine the existing states of cation sites and their transformations in zeolite matrix are discussed. In the last section, the catalytic applications of coordinatively unsaturated sites in zeolite matrix for various important chemical transformations are summarized.
\end{abstract}

(C) 2019, Dalian Institute of Chemical Physics, Chinese Academy of Sciences. Published by Elsevier B.V. All rights reserved.

\section{Introduction}

Catalysis is regarded as the basis of modern chemical industry, which also shows significant impacts on related fields such as materials, energy, environment and healthcare. Currently, about $90 \%$ of all chemical processes are catalyzed and catalysts become the keys to the efficient chemical transformations [1]. Zeolites are well known as the most important catalysts in petrochemical industry [2,3], and with the introduction of metal ion sites, metal-containing zeolites are playing more and more important roles as bifunctional or multifunctional catalysts for the complicated chemical transformations. Herein, these types of materials will be treated as the coordinatively unsaturated sites in zeolite matrix.

\subsection{Hints from coordination catalysis}

The metal ion sites are, in some sense, versatile with a number of functions on the well-defined geometric positions, on which several pairs of electrons are formed so that the reactants can interact with each other in the framework of the complex in advance. It has been observed that some of the atoms or groups called ligands that are coordinated to the metal ion sites show impacts on the activity of these sites. This should be traced back to the interaction between the ligand and the metal ion site. For example, transition metal ion (TMI) sites can act as catalytic centers providing that they have open coordination sites and readily accessible by guest molecules.

\footnotetext{
* Corresponding author. Tel/Fax: +86-22-23500341; E-mail: lild@nankai.edu.cn

This work was supported by the National Natural Science Fundation of China $(21722303,21421001)$, the Municipal Natural Science Fund of Tianjin (18JCJQJC47400, 18JCZDJC37400), and 111 Project (B12015, B18030).

DOI: S1872-2067(19)63381-4 | http://www.sciencedirect.com/science/journal/18722067 | Chin. J. Catal., Vol. 40, No. 9, September 2019
} 
In theory, to describe a coordination catalytic reaction process, the following rules should be followed [4,5]: (1) Transition metal ion A (catalyst) must interact with substrate $B$, where the coordination of $A$ is unsaturated and leads to a charge transfer between $\mathrm{A}$ and $\mathrm{B}$ to form the A-B chemical bond. It is assumed that $B$ is the donor, and the charge of the highest occupied molecular orbital (HOMO) must be transferred to the lowest unoccupied molecular orbital (LUMO) of acceptor A. At the same time, the feedback of another charge must be accompanied to ensure the coordinating activation of substrate B; (2) A or B molecule can be both a donor and an acceptor of the electron pair. The closer the energy level between the two molecules is, the easier it is to react. It is generally believed that to guarantee the successful proceeding of reaction, the energy level difference of frontier molecular orbitals should be at least less than $6 \mathrm{eV}$; (3) Under the dual actions of $\mathrm{HOMO}_{A} \rightarrow \mathrm{LUMO}_{B}$ and $\mathrm{HOMO}_{B} \rightarrow \mathrm{LUMO}_{A}$, it is necessary to weaken or break certain chemical bonds in A or B molecules. Meanwhile, the formation of intermolecular bonds occurs, in order to ensure that the reactions of various elementary steps are carried out in sequence; (4) The necessary and sufficient conditions for the coordination catalytic reaction are that the coordination number of metal ions changes in each elementary step. The valence electron changes of the central ions in the reaction of single metal and non-free radical can meet the 16-18 valence electron law of Tolman; (5) The activity and selectivity of the coordination catalyst mainly depend on the electronic structure of the central ion, the structure of coordination group and the molecular symmetry of the complex.

Catalysis of soluble transition metal complex was first proposed by Roelen et al. [6] who found that cobalt carbonyl complexes could catalyze the reaction of olefins with carbon monoxide and hydrogen to produce aldehydes. The concept of "Coordination Catalysis" was proposed by Natta in 1957 when talking about the catalytic properties of a Ziegler-Natta catalyst [7]. In this catalytic pattern, the catalyst coordinates with the reaction molecule and puts it into the active state in favor of further reaction, thus accelerating the reaction. The final product decomposes from the central metal of the catalyst. Nowadays, coordination catalysis has been recognized as a main type of homogeneous catalysis (other types: acid-base catalysis and free radical catalysis) and it has been applied in various important reactions such as hydrogenation, oxidation, carbonylation, hydroformylation and $\mathrm{C}-\mathrm{C}$ bond coupling $[4,8]$.

The carbonylation of methanol to acetic acid, catalyzed by rhodium-complex and developed by Monsanto Company [9], is presented below as a clear example of coordination catalysis. The total reaction equation is very simple $\left(\mathrm{CH}_{3} \mathrm{OH}+\mathrm{CO} \rightarrow\right.$ $\mathrm{CH}_{3} \mathrm{COOH}$ ) while the catalytic cycle contains oxidative addition, ligand migration, $\mathrm{CO}$ insertion and reductive elimination (Scheme 1). The cyclic changes in the coordination numbers of Rh are clearly identified.

Despite of the advantages in good activity, high selectivity and clear reaction mechanism, coordination catalysis with metal complexes generally suffers from costly separation process and poor recyclability. These drawbacks might be partially overcome through immobilization of metal complex catalysts

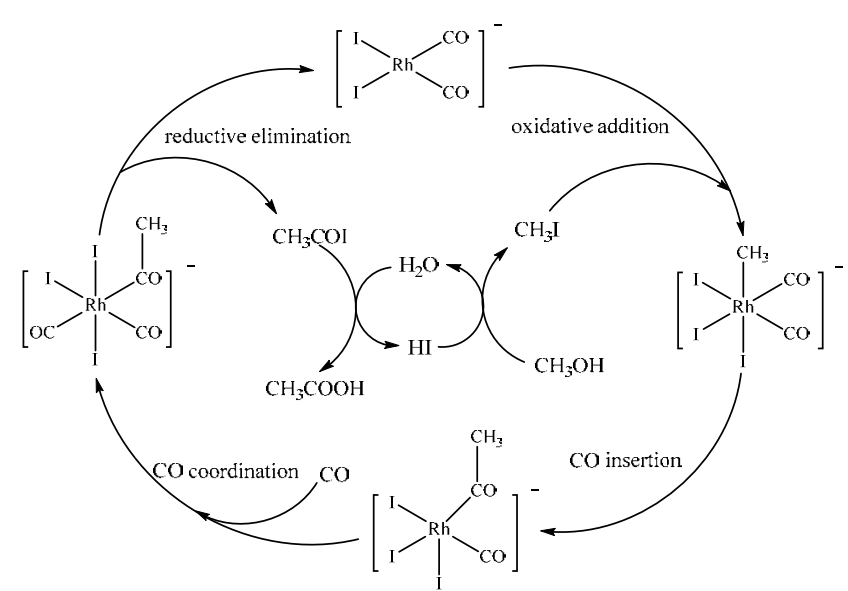

Scheme 1. Catalytic cycle of methanol carbonylation to acetic acid catalyzed by rhodium-complex.

on solid carriers such as polymers and silica, and construction of quasi-homogeneous coordination catalysis system. On the other hand, the initial concept of coordination catalysis is by no means limited to the use of metal organic complexes as catalysts, and the building of inorganic catalysts that act like organic complexes should be an ideal solution to the above-mentioned problems. In this context, coordinatively unsaturated sites in zeolite matrix become research hotspots, which will be focused in this review article.

\subsection{Zeolites and their structural features}

Zeolites are three-dimensional microporous crystalline aluminosilicates with the well-defined channels and cavities having window diameters of $<1 \mathrm{~nm}$. The framework of aluminosilicate is known to be negatively charged and should be neutralized by extra-framework cations. The primary building blocks of zeolite framework are the $\left[\mathrm{SiO}_{4}\right]^{4-}$ and $\left[\mathrm{AlO}_{4}\right]^{5-}$ tetrahedrons. Three-dimensional networks are formed through the corner-sharing sharing of the four $\mathrm{O}$ atoms. Owing to the crystalline ordering, zeolites possess ordered pores and cavities with specific sizes and shapes. As a matter of fact, the strictly alternating negatively charged $\mathrm{Al}-\mathrm{O}$ and positively charged $\mathrm{P}-\mathrm{O}$ tetrahedrons, i.e. $\left[\mathrm{AlO}_{4}\right]^{5-}$ and $\left[\mathrm{PO}_{4}\right]^{3-}$, could be used as the primary tetrahedral building blocks of zeolitic structures called microporous aluminophosphates (AlPO- $x$ ). Presently, accounting to 239 various structure types are officially recognized and summarized by the Structure Commission of IZA (International Zeolite Association). These zeolite frameworks have different sizes, shapes, dimensions and connectivity of channels from 8 to 30 rings. Some of them can be found as minerals in nature, while most are artificially synthesized. The development undergoes several important processes from natural zeolites to artificial synthesis, from low-silica zeolites to high-silica ones and from aluminosilicates to AlPO- $x$ molecular sieves. However, only comparatively few secondary building units (SBUs, groups of several T sites) exist, and most industry-relevant zeolites can be grouped into two categories: (1) pentasil zeolites, which are formed by five-membered rings (5MR), show a clear one- or 
two-dimensional channel structure, and (2) zeolite structures based on double six-membered ring (D6R) prisms, which have three-dimensional cavities. The most important zeolites are those with topological structures of MFI, FAU and CHA. In Table 1 , the unit cell dimensions and channel systems of these zeolites are briefly summarized. The separation of molecules can be achieved according to their molecular sizes in comparison with zeolite pores i.e. the so-called molecular sieving effect. These special properties are called as shape selectivity in zeolite catalysis.

Zeolite framework is widely open that can accommodate molecules and ions. In this context, zeolites have been extensively investigated, and commercially applied as ion exchangers, molecular sorbents, and heterogeneous catalysts in industrial processes. The extra-framework cations existing in zeolites can play important roles in controlling the adsorption and catalytic properties of platform zeolites. According to the experimental and theoretical investigations, it is generally accepted that there are three potential sites for the introduced extra-framework TMIs denoted as $\alpha, \beta, \gamma$ for topological struc- ture of silicon-rich pentasil zeolites (MOR, FER, MFI and BEA) or I, II, III for topological structure of aluminium-rich zeolites (LTA, CHA and FAU), respectively (Fig. 1). Actually, the TMIs prefer to occupy the most favorable exchange sites and tend to achieve their maximum coordination number. With FAU as an example, the TMIs are preferentially located at sites I (inside the hexagonal prisms) or sites I' (in the sodalite cages) after dehydration. It should be noted that the $\mathrm{O}$ atoms of the Al tetrahedron are preferentially coordinated to the TMIs during dehydration, leading to site distortion and deviation of TMIs from the center of the 6MRs. More accessible exchange sites in the super-cages are subsequently occupied (sites II and III) at higher loadings. Considering another example of MFI, TMIs can locate in the 10-membered-ring (10MR) channels or at the intersections of channels. They are priorly coordinated to the 6-membered-ring (6MR) containing one or two Al tetrahedrons, but 5-membered-ring (5MR) with only one Al site should not be excluded. The same circumstances hold for the topology of MOR with its $12 \mathrm{MR}$ and 8MR interleaved channel systems.

Table 1

The pore sizes, unit cell compositions, building units and dimensionality of the channel systems of CHA, LTA, FAU, MOR, MFI, *BEA and FER.

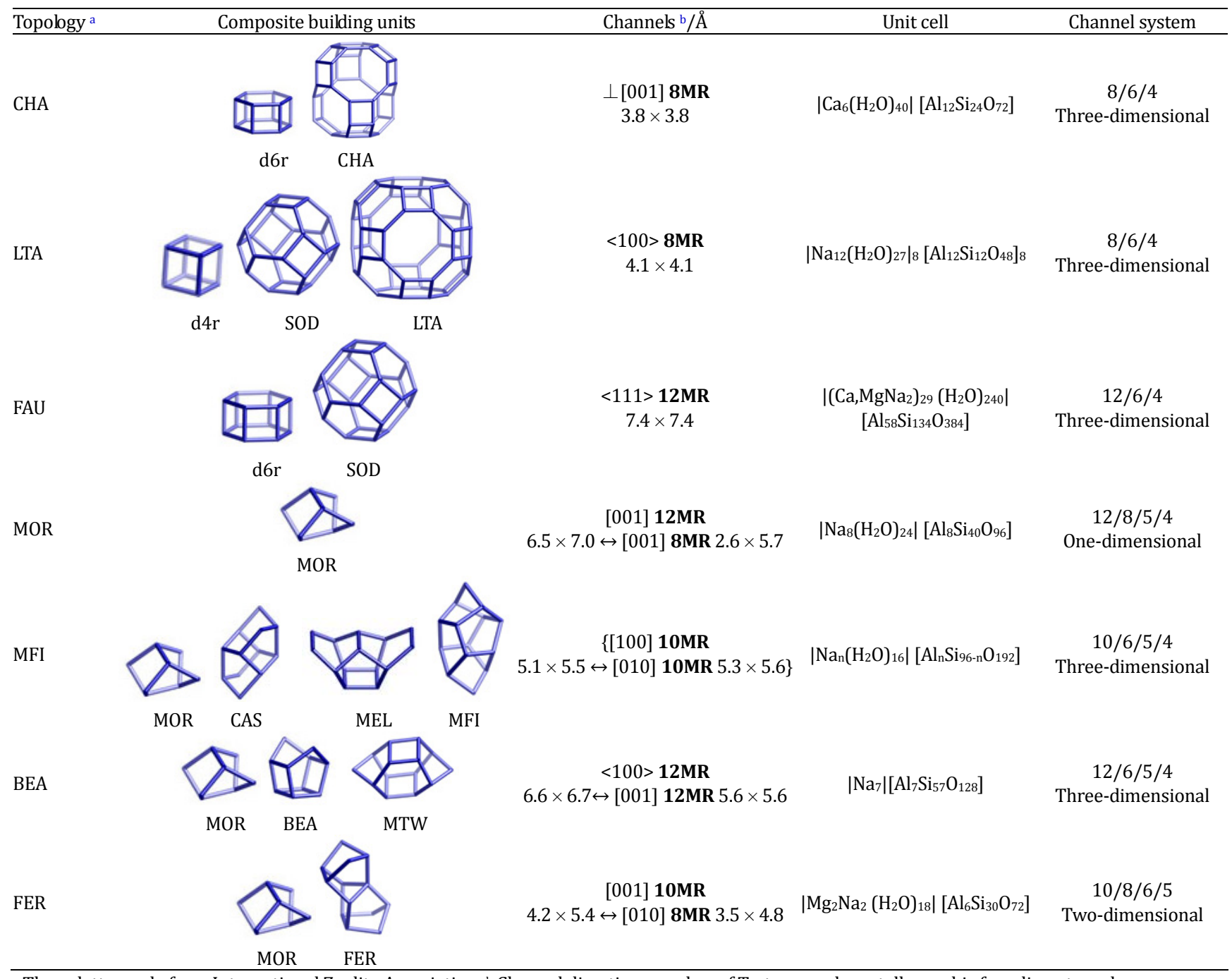

a Three-letter code from International Zeolite Association; ${ }^{\mathrm{b}}$ Channel direction, number of T-atoms and crystallographic free diameters shown. 


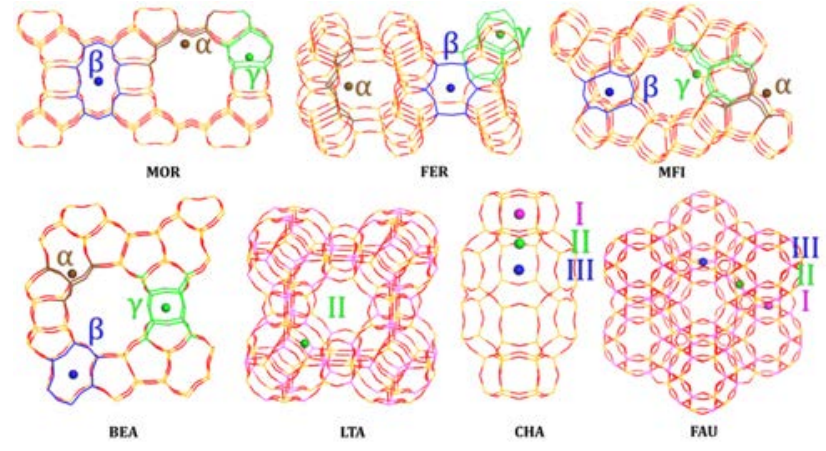

Fig. 1. Typical sites for extra-framework transition metal ions denoted as $\alpha, \beta$ and $\gamma$ for topological structure of pentasil zeolites or I, II and III for topological structure of aluminium-rich zeolites.

In addition to the extra-framework positions, TMIs such as $\mathrm{Ti}^{4+}$ [10] and $\mathrm{Zr}^{4+}$ [11], and some main-group metal ions such as $\mathrm{Ga}^{3+}[12,13]$ and $\mathrm{Sn}^{4+}[14]$, can be incorporated into the framework of zeolites, i.e. heteroatom substituted zeolites. The structural features of heteroatom substituted zeolites are usually discussed in comparison with parent zeolites without heteroatoms and the zeolite framework can be view as ligands of heteroatoms (vide infra).

The metal sites in the framework and extra-framework positions of zeolites are collectively referred to as metal ion sites in zeolite matrix. These metal ion sites can be coordinatively unsaturated or transformed to the coordinatively unsaturated states upon certain treatments. In principle, coordinatively unsaturated sites in zeolite matrix can make good use of the concept of both coordination and zeolite chemistry, and take the advantages of coordination catalysis for applications in heterogeneous catalysis.

\section{Construction of coordinatively unsaturated sites in zeolite matrix}

Owing to their promising catalytic behaviors in various important reactions, TMI-containing zeolites have been extensively investigated by both academic community and industry. By placing TMIs within the zeolite matrix, well dispersed cation sites can be expected since the particle sizes of these sites are regulated by zeolite structure to a great extent. Undoubtedly, the catalytic behaviors of such catalysts should be somewhat different from traditional supported catalysts.

The following issues should be concerned and addressed when constructing coordinatively unsaturated TMI sites within zeolite matrix: (1) introducing highly dispersed sites to zeolite and preventing them from aggregation; (2) matching between TMI guests and zeolite hosts; (3) activating TMIs to coordinatively unsaturated sites prior to catalytic applications. Currently, many strategies have been developed to construct coordinatively unsaturated sites within zeolite matrix, including ion-exchange followed by calcination, diffusion impregnation of TMI precursors followed by calcination, direct hydrothermal synthesis, encapsulating complexes of TMIs within zeolite and post-synthesis modifications after dealumination. For direct hydrothermal synthesis and post-synthesis modifications, TMIs can be incorporated into zeolite framework under the precisely controlled conditions. While other strategies exclusively lead to TMIs at the extraframework positions.

\subsection{Ion-exchange followed by calcination}

Ion-exchanged is a primary means of introducing TMIs into the zeolite matrix due to its low cost and simple operation. A common wet ion-exchange (WIE) is performed in aqueous medium using soluble precursors of TMIs, for example nitrates or acetates, at room temperature or elevated temperature below $373 \mathrm{~K}$, followed by filtration and washing with deionized water until the washing liquor is free of TMIs. The duration of WIE process can be in the range from a few hours to serval days, depending on the types of TMIs and zeolite hosts. The level of exchange is controllable by adjusting the duration of exchange, temperature and metal ion precursors. In order to avoid the unexpected side reactions such as hydroxides precipitation and zeolite lattice destruction, the WIE should be performed in a proper dilute, neutral to slightly acidic medium allowing for the aqueous solutions of TMIs are acidic in most cases.

Bivalent ions are usually exchanged in the fully hydrated forms, for example hexaaquo complexes such as $\left[\mathrm{Co}\left(\mathrm{H}_{2} \mathrm{O}\right)_{6}\right]^{2+}$ and $\left[\mathrm{Cu}\left(\mathrm{H}_{2} \mathrm{O}\right)_{6}\right]^{2+}$, within the supercages and channels of zeolites $[15,16]$. Heating in the oxygen or air results in the release of water molecules and the migration of TMIs towards the smaller cavities of zeolites, occupying the well-defined cation sites. Since it is very difficult to provide enough oxygen coordination atoms in a certain ring in high $\mathrm{Si} / \mathrm{Al}$ ratio zeolites, the TMIs in dehydrated Metal-zeolites tend to form coordinatively unsaturated states, which can provide ideal sites for reactants in catalytic reactions. This method has been employed to prepare MetalII-zeolites, for example Cu-zeolites (MFI, CHA, FAU, LTA and MOR) [17,21], Co-Zeolites (MFI, FAU and FER) [22]-[24] and Ni-zeolites (LTA, MFI, FAU, BEA and MOR) $[25,28]$. It is worth noting that there are hardly any 6 or 8 member rings that contain three $\mathrm{Al}$ atoms for charge compensation, the exchange of ferric ions $\left(\mathrm{Fe}^{3+}\right)$ is hard to achieve. In fact, ferrous ions $\left(\mathrm{Fe}^{2+}\right)$, obtained by adding iron into ferric solution under an inert surrounding, are generally employed to prepare Fe-zeolites [29].

Hence, what calls for special attention here is the Al distribution in zeolite framework for balancing the positive charges of TMIs since the framework $\mathrm{Al}$ atoms induce the local negative charges. The distribution of $\mathrm{Al}$ atoms in zeolite framework can be monitored by a mature methodology using $\mathrm{Co}^{\mathrm{II}}$ ions as probes to indicate adjacent $\mathrm{Al}$ atoms, along with ${ }^{27} \mathrm{Al}$ and ${ }^{29} \mathrm{Si}$ MAS NMR analysis. The $\left[\mathrm{CoII}^{\mathrm{II}}\left(\mathrm{H}_{2} \mathrm{O}\right)_{6}\right]^{2+}$ ion-exchange capacity of Co-zeolites (hydrated) parallels to framework $\mathrm{Al}$ atoms that are close enough to balance the charge of $\left[\mathrm{Co}^{\mathrm{II}}\left(\mathrm{H}_{2} \mathrm{O}\right)_{6}\right]^{2+}$, and the concentrations of bare $\mathrm{Co}^{\mathrm{II}}$ ions at the $\alpha, \beta$ and $\gamma$ sites in dehydrated Co-zeolites (coordinating exclusively to framework oxygen atoms) correspond to two $\mathrm{Al}$ atoms that are localized at a single 6/8MR ring in the cation sites. For illustrating the $\mathrm{Al}$ distribution in the framework of MFI zeolites, Na-ZSM-5, for instance, is exchanged to a maximum degree (repeated several times) with aqueous solution of $\mathrm{Co}^{\mathrm{II}}$ nitrate $(0.05 \mathrm{M})$ at room 
temperature, followed by thorough washing with deionized water. In strict compliance with these conditions of $\mathrm{Co}^{\mathrm{II}}$ ion-exchange (Na-form, room temperature and 0.05 molarity), the exclusive and uniform exchange of $\left[\mathrm{Co}^{\mathrm{II}}\left(\mathrm{H}_{2} \mathrm{O}\right)_{6}\right]^{2+}$ ions adjacent to $\mathrm{Al}$ atoms in hydrated Co-zeolites is guaranteed, which can be monitored by the characteristic UV-Vis spectra of the $\left[\mathrm{Co}^{\mathrm{II}}\left(\mathrm{H}_{2} \mathrm{O}\right)_{6}\right]^{2+}$ ions in the hydrated Co-ZSM-5 zeolites. The exchange degree of $\mathrm{Co}^{\mathrm{II}}$ hexaquo-complexes represents the $\mathrm{Co}^{\mathrm{II}}$ ion-exchange capacity of the zeolite [30].

A major drawback of wet ion exchange method is that the exchange process has to be repeated several times to obtain the expected high ion-exchange level, making WIE a time-consuming process with the production of large amounts of waste solutions. Meanwhile, the cations are strongly solvated or available only in complexes, which are too bulky to enter the narrow pores (6MR) of zeolites, for example, the CHA zeolites with pore opening of $0.38 \mathrm{~nm}$ in diameter. In addition, in-going ions like $\mathrm{Cu}^{\mathrm{I}}$ and those that are insoluble or do not exist in an aqueous solution cannot be achieved by WIE, which limits its applications. For these reasons, solid-state ion-exchange (SSIE) is developed. Slinkin et al. [31] focused on the solid-state introduction of TMIs into high-silica zeolites such as ZSM-5 and mordenite as early as 1980 s. The carefully grinded and intimate mixture of zeolites in the $\mathrm{NH}_{4}{ }^{+}$or $\mathrm{H}^{+}$form and metal precursors such as salts (organic or inorganic) and oxides are subsequently heated in a stream of inert gas or in high vacuum to remove the volatile products such as hydrogen halides, ammonia, water, and etc. To bring the process of SSIE to its maximum, a reaction temperature of 500-1000 $\mathrm{K}$ and a reaction time of several hours are generally sufficient. The following reactions occur during SSIE of zeolites (Na-Z or $\mathrm{H}-\mathrm{Z})$ by $\mathrm{Cu}$ precursors $\left(\mathrm{CuX}_{2}\right)$ :

$$
\begin{aligned}
\mathrm{CuX}_{2}+\mathrm{Na}_{2}-\mathrm{Z} & \rightarrow \mathrm{Cu}-\mathrm{Z}+2 \mathrm{NaX} \\
\mathrm{CuX}_{2}+\mathrm{H}_{2}-\mathrm{Z} & \rightarrow \mathrm{Cu}-\mathrm{Z}+2 \mathrm{HX}
\end{aligned}
$$

Bell et al. [32] and Hutchings et al. [33] prepared Fe-ZSM-5 from the mixture of $\mathrm{FeCl}_{3} / \mathrm{Fe}$ (acac) 3 and HZSM- 5 followed by heat treatment and washing with the deionized water to remove the remaining chloridions. Likewise, considering the tendency of ferric salts to form dinuclear clusters in the solution and subsequent precipitation as hydroxides as well as the insufficient local charge compensation from the zeolite framework, it is preferred to use ferrous salts for SSIE. On the other hand, due to the low chemical stability of the $\mathrm{Fe}^{\mathrm{II}}$ state, preparation in controlled atmosphere or in the presence of reducing agents is often required to avoid the oxidation of $\mathrm{Fe}^{\mathrm{II}}$ to $\mathrm{Fe}^{\mathrm{III}}$. Shwan et al. [34] exposed the physical mixtures of copper oxides $\left(\mathrm{Cu}_{2} \mathrm{O}\right.$ and $\left.\mathrm{Cu}^{\mathrm{II}} \mathrm{O}\right)$ and zeolites in their proton forms (MFI, $\mathrm{BEA}$, and $\mathrm{CHA}$ ) into various combinations of $\mathrm{NO}, \mathrm{NH}_{3}, \mathrm{O}_{2}$, and $\mathrm{H}_{2} \mathrm{O}$, and exchanged the formed $\left[\mathrm{Cu}^{\mathrm{I}}\left(\mathrm{NH}_{3}\right)_{x}\right]^{+}(x \geq 2)$ complexes with protons in zeolite. A mild dispose can avoid the affection of milling toward the zeolite structure by means of preparing a suspension of powdered salt and the zeolite in an inert solvent like hexane. The solvent can be removed by a simple rotary evaporation after fully blended. The desorbed hydrogen halides or ammonia in the gas phase at elevated temperatures during the ion exchange may attack the lattice, leading to the destruction of zeolite lattice especially with the presence of water. In this context, a gas-phase ion exchange is performed to preserve the zeolite matrix under the relatively mild conditions. Gas-phase exchange is mainly applied in the preparation of $\mathrm{Cu}$-zeolite, and it occurs between the protonic form of the zeolite and the vapor of $\mathrm{Cu}^{\mathrm{I}} \mathrm{Cl}$. So far, $\mathrm{Cu}^{\mathrm{I}}$-exchanged zeolites with topologies of MFI, FAU and MOR have been successfully prepared via gas-phase ion-exchange, and no evidence could be found for the presence of $\mathrm{Cu}^{\mathrm{II}}$ ions or micro-aggregates of copper species $[21,35,36]$.

In a word, favored by its simplicity and economic advantages, ion-exchange of TMIs is the most straightforward and the most frequently used means to introduce coordinatively unsaturated sites into the zeolite matrix.

\subsection{Diffusion impregnation followed by calcination}

Traditionally, the primary impregnation process was accomplished through a simple mixture of TMI precursor aqueous solution and zeolite host at room temperature or a bit higher temperature followed by the removal of water. The TMI-containing hydrated ions or hydroxides show stronger self-interaction than their interaction with zeolite matrix. Through calcination processes, the TMIs aggregate and migrate to form the multinuclear metal oxides of different sizes covering the outer surface of zeolites. Under the reaction conditions, only the exposed sites are available and active for the desired catalytic conversions. To maximize the utilization of TMIs and reinforce the interaction between TMIs and zeolite matrix, a diffusion impregnation method is proposed. A typical operation is described as follows: the dehydrated zeolites are suspended and vigorously stirred in the solution of organometallics complexes like $\mathrm{Fe}(\mathrm{acac})_{3}$ in organic solvents (for example inactive toluene), which are then calcined in air with a heating ramp of $2 \mathrm{~K} / \mathrm{min}$ to $823 \mathrm{~K}$ and isothermal for $10-30 \mathrm{~h}$ to remove the organic material completely. Upon calcination, the ligand acetylacetone is decomposed to $\mathrm{CO}_{2}$ and $\mathrm{H}_{2} \mathrm{O}$ :

$$
\begin{aligned}
& 2 \mathrm{Fe}(\mathrm{acac})_{3} / \mathrm{H} \text {-zeolite }+35 \mathrm{O}_{2} \rightarrow \\
& 2 \mathrm{Fe}^{3+}-\text { zeolite }+30 \mathrm{CO}_{2}+22 \mathrm{H}_{2} \mathrm{O}
\end{aligned}
$$

Sels et al. $[37,38]$ have successfully prepared Fe-zeolites (MOR, MFI, FER, CHA and BEA) with the so-called $\alpha$-Fe sites through the diffusion impregnation method. The Fe loadings in Fe-zeolites should be carefully controlled to avoid the formation of $\mathrm{Fe}_{2} \mathrm{O}_{3}$ and $\mathrm{Fe}_{3} \mathrm{O}_{4}$ nanoparticles considering the limited capability of charge compensation to balance the $\mathrm{Fe}^{3+}$ ions especially for zeolites with high $\mathrm{Si} / \mathrm{Al}$ ratios. After the intense scrutiny, we propose the major driven force for diffusion impregnation is the interaction or reaction between organometallic complexes and the Brønsted acid sites in zeolites. Obviously, the diffusion impregnation should not be limited to the reaction in liquid-phase, and the reaction between zeolite solids and gas-phase organometallic complexes (mostly sublimated) should be more suitable. This process has been developed as the surface organometallic chemistry reaction or grafting method, which has been involved in the preparation of Fe-zeolites [39,40] and Co-zeolite [41].

\subsection{Direct hydrothermal synthesis}


The direct hydrothermal synthesis of noble metal-containing zeolites is very difficult because noble metal precursors undergo easy precipitation in the alkaline conditions of synthesis. In contrast, TMIs, especially the first-row TMIs, can survive in the more rigorous conditions, making the direct hydrothermal synthesis of TMI-containing zeolites more feasible. Obviously, the simplest way of introducing TMIs to the zeolite matrix is adding TMI precursors directly into the typical synthesis gel and TMIs are expected to build the zeolite structure units with $\left[\mathrm{SiO}_{4}\right]^{4-}$ tetrahedrons, leading to the heteroatoms incorporation into zeolite framework. However, this route is only effective for a few types of TMIs, for example $\mathrm{Ti}^{3+}$ and $\mathrm{Fe}^{3+}$. The main-group metal ions such as $\mathrm{Ga}^{3+}$ (belonging to the same group with $\mathrm{Al}^{3+}$ in the periodic table) and $\mathrm{Sn}^{4+}$ (belonging to the same group with $\mathrm{Si}^{4+}$ ) can also be incorporated into zeolite framework via direct hydrothermal synthesis. Generally, the loadings of framework heteroatoms from direct hydrothermal synthesis are relatively low, for example $<2 \mathrm{wt} \%$, due to the restriction from zeolite structure.

The direct hydrothermal synthesis of Ti-zeolites, which can be traced back to the beginning of the 1980s with the discovery of titanium silicalite-1 (TS-1) by Taramasso et al. [42], has been well documented in the past decades. Since then, a series of Ti-zeolites including TS-2 [43], Ti-ZSM-12 [44], TAPSO-5 [45], TAPSO-34 [46,47], Ti-beta $[48,49]$ and Ti-MWW [50] have been reported, and special attention is focused on more active Ti-zeolites with various channel systems. Since Ti is the substitution of $\mathrm{Si}$, a tetra-coordinated source of titanium, titanium butoxide (ТВОT), is usually added to the synthesis gel of zeolite. Different organic structure directing agents (OSDAs), ranging from tetrapropylammonium hydroxide (TPAOH), tetraethylammonium hydroxide (TEAOH) to cyclohexylamine (CHA) have been employed during the hydrothermal synthesis with aim to obtain different topological structure of zeolites. In some cases, the hydrolysis of the TBOT and precipitation of $\mathrm{TiO}_{2}$ are prevented through the addition of $\mathrm{H}_{2} \mathrm{O}_{2}$ to the synthesis gel, which leads to the more stable peroxo-Ti species [45].

The existence of framework Fe species is discovered accidentally since they were once regarded as the impurity of the material. Subsequently, framework Fe species are found to play an important role as the active sites for many catalytic reactions. In this context, the Fe-zeolites with different topological structures have been synthesized hydrothermally. Fe-ZSM-5 is among the most used Fe-zeolites owing to its unique catalytic performance in some selective oxidation reactions (vide infra). The synthesis of Fe-ZSM-5 can be accomplished by adding ferric nitrate as source of the Fe to the synthesis gel in the presence OSDAs such as TPAOH and TPABr. In order to prevent the hydrolysis of $\mathrm{Fe}^{3+}$, an acidified pre-treatment is applied in some recipes [33,51,52].

A modified route of normal hydrothermal synthesis is the dry gel conversion which is primarily employed in the synthesis of Ti- and Sn-zeolites. In the dry gel conversion synthesis of zeolites, the solid gels are placed at the middle of the vessels and the solution of OSDAs are at the bottom. The OSDAs and water required for crystallization are transmitted by steam generated from heating. The dry gel conversion is a simple and environment friendly route due to the indirect contact of the solid gels and liquid OSDAs, which significantly reduces the consumption of OSDAs. Besides, the reduced usage of water generates less liquid waste. Tatsumi et al. [53] successfully prepared Ti-beta zeolite through the dry gel conversion route. Typically, a high yield of $>95 \%$ was achieved, and the content of Al species in the zeolite could be controlled $\left(n_{\mathrm{Si}} / n_{\mathrm{Al}}=330\right)$. Similarly, Al-free Sn-beta zeolite with $\mathrm{n}_{\mathrm{Si}} / \mathrm{n}_{\mathrm{Sn}}$ ratio of 83 was successfully prepared by steam assisted dry gel conversion and the factors controlling the formation of zeolite were studied in details $[54,55]$. The cartoon of this strategy is shown in Fig. 2 for a direct view [56].

To have a brief summary, the direct hydrothermal synthesis or dry gel conversion is a desired route to obtain heteroatom-containing zeolites. More importantly, all the framework heteroatoms should, in principle, be tetrahedrally coordinated and the construction of coordinatively unsaturated TMIs is very clear. On the other hand, the incorporation of heteroatoms is seriously affected by their sizes and charges (matching with $\mathrm{Si}^{4+}$ ). In fact, the direct hydrothermal synthesis of heteroatom-containing zeolites is difficult to achieve and some results are hotly debated.

\subsection{Encapsulating complexes of TMIs within zeolite}

For complexes of TMIs, a concept of zeolite encapsulation is proposed. Typically, three representative strategies have been developed in encapsulation of complexes of coordinatively unsaturated TMIs in zeolite structure: (1) the templating strategy, (2) the ship-in-bottle strategy, and (3) the flexible ligand strategy, as showed in Scheme 2.

For strategy (1), the preformed well-designed complexes of TMIs are used as the sole templates or co-templates together with other OSDAs around which zeolites are crystallized, like a 'build-bottle-around-ship' process. In this context, the complexes of TMIs should be stable enough under the harsh conditions of zeolite synthesis such as high $\mathrm{pH}$ values and high temperatures. This strategy looks very similar to the direct hydrothermal synthesis and the major difference lies in the synthesis results. That is, direct hydrothermal synthesis leads to framework incorporation while encapsulating leads to confined complexes of TMIs, which can transform to extraframework TMIs upon removal of organic ligands. For example, Xiao et al. [57] used low-cost copper-ammonium complex, i.e. Cu-TEPA, as a novel template to synthesize $\mathrm{Cu}-\mathrm{SSZ}-13$ by one-pot hydro-

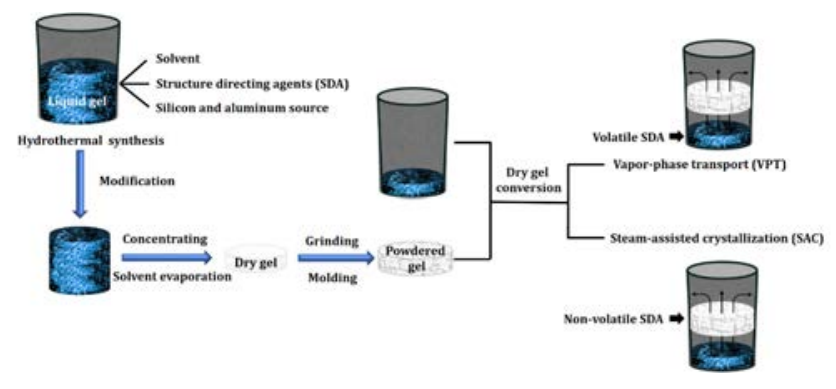

Fig. 2. Cartoon for the synthesis of heteroatom-containing zeolites via dry-gel conversion, reproduced from Ref. [56] with permission. 


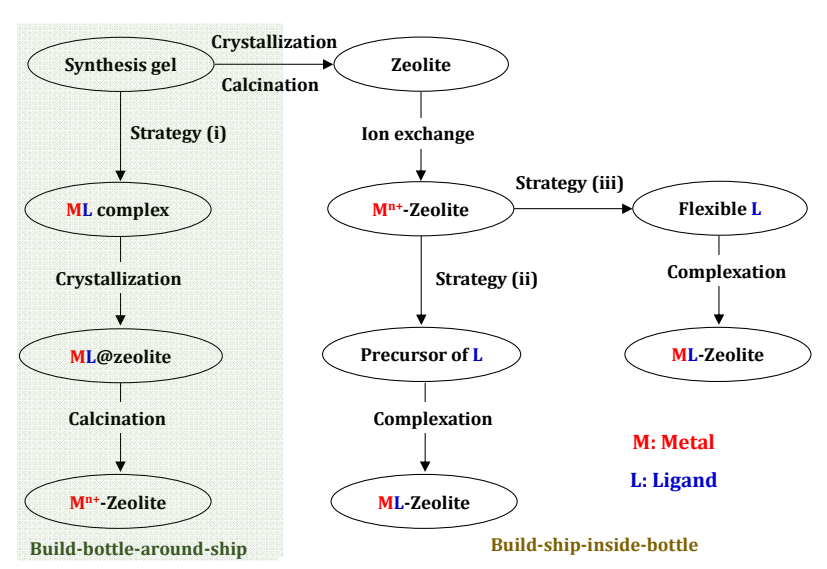

Scheme 2. Strategies to encapsulating complexes of coordinatively unsaturated TMIs in zeolite matrix.

thermal route. High $\mathrm{Cu}$ loading and good dispersion of $\mathrm{Cu}$ species were simultaneously achieved in the calcined product. Compared with the conventional ion exchange method, the direct hydrothermal strategy of introducing $\mathrm{Cu}^{2+}$ species into the zeolite matrix greatly enhanced the efficiency of $\mathrm{Cu}$ species. This strategy was extended to the synthesis of Cu-SAPO-34 using $\mathrm{Cu}$-TEPA and morpholine as templates [58]. Similarly, Cu-SAPO-18 was successfully synthesized by using Cu-TETA and $\mathrm{N}, \mathrm{N}$-diisopropylethylamine as templates [59]. In addition to Cu-zeolites, Co-zeolites [60], Fe-zeolites [61,62], Ni-zeolites [63] or even Sn-zeolites [64] have been successfully prepared via similar strategies.

The 'build-ship-inside-bottle' strategy means that the complexes of TMIs are confined in the cavities of target zeolite hosts by some particular means. The specific channel system of zeolites has a restriction effect on the entering and leaving of molecules, so that the molecules are trapped in the zeolite cavities and cannot easily escape, just like building a ship in a bottle. Strategies (2) can also be seen as the chemical synthesis in a cage, wherein the precursors (for example o-dicyanobenzene) of ligand diffuse into the cages and coordinatively polycondense around the TMIs to form metal complexes like phthalocyanin (Pc). The size of as-prepared complexes is larger than the diameter of pores and can therefore be stabilized by the zeolites [65]. Strategies (2) and (3) are relatively more adaptive to the encapsulation of a wide range of complexes of TMIs in zeolites. Both approaches have been extensively investigated and employed to encapsulate Schiff bases, metalloporphyrins, metallophthalocyanines, etc. [66,67]. Generally speaking, when the sizes of ligands are larger than the opening diameters of zeolite channels, strategy (2) is used, wherein the ligands are constructed within the micropores of zeolites and then complexed with the resident TMIs. On the other hand, when the sizes of ligands are smaller than the opening diameters of zeolite and the ligands are flexible to diffuse into the zeolite cages to react with the previously exchanged TMIs, strategy (3) is preferred. The sizes of the formed complexes should be larger than the opening diameters of zeolite channels, and in such a way, the complexes of TMIs are encapsulated in zeolite matrix. This strategy is widely used in the encapsulation of the
Salen-metal complexes, and Salen-(Co, $\mathrm{Fe}, \mathrm{Mn}$ and $\mathrm{Cu}$ ) complexes have been successfully encapsulated in the supercage structure of zeolites $[68,69]$. Although this flexible ligand strategy is simple to operate, there are many TMIs in the cage that are not coordinated with the ligands, thus leading to the non-uniform distribution of composite materials. Through 'build-ship-inside-bottle' strategy, various functional complexes can be confined in zeolite cages and directly used as immobilized organometallic catalysts, which is beyond the scope of this article and will not be further discussed.

\subsection{Post-synthesis modifications after dealumination}

In the direct hydrothermal synthesis of heteroatoms-containing zeolites with large ionic radius (compared with $\mathrm{Si}^{4+}$ ), the self-nucleation in the primary synthesis gel is very difficult and, therefore, more vigorous conditions are required (longer crystallization time and in the presence of extra mineralizer such as fluorions). As a result, the loadings of heteroatoms are usually very low and the energy consumption as well as the cost of zeolite synthesis is significantly increased. To solve the problems, post-synthesis strategy for introducing heteroatoms to zeolite framework has been developed.

In 1982, Barrer [70] had already presented a special report on the preparation of heteroatoms-containing zeolites via post-synthesis modifications. In brief, Al atoms were removed from framework of aluminosilicate zeolites with the creation of structure vacancies, which could be re-occupied by heteroatoms under suitable conditions. In early researches, the successful incorporation of heteroatoms into zeolite framework was hotly debated, probably due to the complicated species introduced to zeolite framework via this strategy (vide infra) and the insufficient characterization techniques. In the past decades, the post-synthesis strategy underwent rapid development. For example, Dzwigaj et al. [71] reported the fully dealumination of commercial beta zeolite by treating them in concentrated salpeter solution ( $>10 \mathrm{~mol} / \mathrm{L}$ ) and the subsequent incorporation of Ti heteroatoms from $\mathrm{TiCl}_{4}$ precursor to derive Ti-beta zeolite. It was proposed that organometallic $\mathrm{Cp}_{2} \mathrm{TiCl}_{2}$ could also be used as Ti precursor to prepare Ti-zeolites or even Ti-containing mesoporous silica materials [72-74]. Compared with $\mathrm{TiCl}_{4}$, the key advantage of $\mathrm{Cp}_{2} \mathrm{TiCl}_{2}$ lied in its relative chemical inertness and less sensitive to humidity, making $\mathrm{Cp}_{2} \mathrm{TiCl}_{2}$ easier to handle during preparations. However, a large amount of toxic trichloromethane was required to be used as solvent when dealing with $\mathrm{Cp}_{2} \mathrm{TiCl}_{2}$ [71], and more importantly, a lack of reproducibility was claimed. In this context, solid-state reaction called dry impregnation is developed as an alternative to liquid-phase reaction for the incorporation of heteroatoms in dealuminated zeolite frameworks. The unwanted hydrolysis of metal precursors can be significantly suppressed and the resulting lack of reproducibility might be addressed. In a typical operation, solid precursors of TMIs and dealuminated zeolite hosts are mixed and calcined to derive the heteroatoms-containing zeolites. Hermans et al. [75] successfully prepared Sn-beta with high Sn loadings $(\sim 10 \mathrm{wt} \%)$ through the dry impregnating of stannous acetate precursor to dealumi- 
nated beta zeolite. In another work, Li et al. [10] prepared Ti-beta sample through similar two-step post-synthesis strategy which consisted of (1) creating vacant T sites with associated silanol groups by dealumination of parent H-beta and (2) subsequent dry impregnation of the resulting Si-beta with organometallic $\mathrm{Cp}_{2} \mathrm{TiCl}_{2}$. In this process, the liquid-phase reaction was replaced by solid-state reaction (dry impregnation) and the toxic solvent trichloromethane was abandoned, making this route greener and more easily reproduced. This route was then extended to the preparation of Zr-beta [11], Sn-beta [14] , Ce-beta [76] and even Pb-beta with ultra large ionic radius [77].

Although the initial proposal of the post-synthesis modification strategy is to replace the framework $\mathrm{Al}$ atoms by heteroatoms, the existing states of heteroatoms are somewhat different to those of $\mathrm{Al}$ atoms. Through sufficient debates, it has been generally acknowledged that heteroatoms can locate in the framework positions in both closed and different open configurations (Fig. 3) and the detailed discussion on this issue will be present in the next section. Undoubtedly, post-synthesis modifications after dealumination should be a general top-down strategy to heteroatom-containing zeolites. In fact, many TMIs and some main-group metal ions with a wide range of loadings $[71,75,86]$, for example $1-10 \mathrm{wt} \%$, have been successfully incorporated into zeolite framework (Fig. 3). Beta zeolite is mostly investigated as zeolite host due to its controllable dealumination and well preserved zeolite structure even after fully dealumination [87].

\section{Characterization of coordinatively unsaturated sites}

The characterization of coordinatively unsaturated sites is a very important but difficult task. The characterization results can provide direct guidance on the construction of coordinatively unsaturated sites in zeolite matrix. On the other hand, the characterization results can be associated with the catalytic performance, building structure-activity relationship together. In this section, we will summarize the representative and emerging characterization techniques for coordinatively unsaturated sites in zeolite matrix. Other techniques might show the potential for this purpose and may have already been employed, not all of them can be included in this review article.

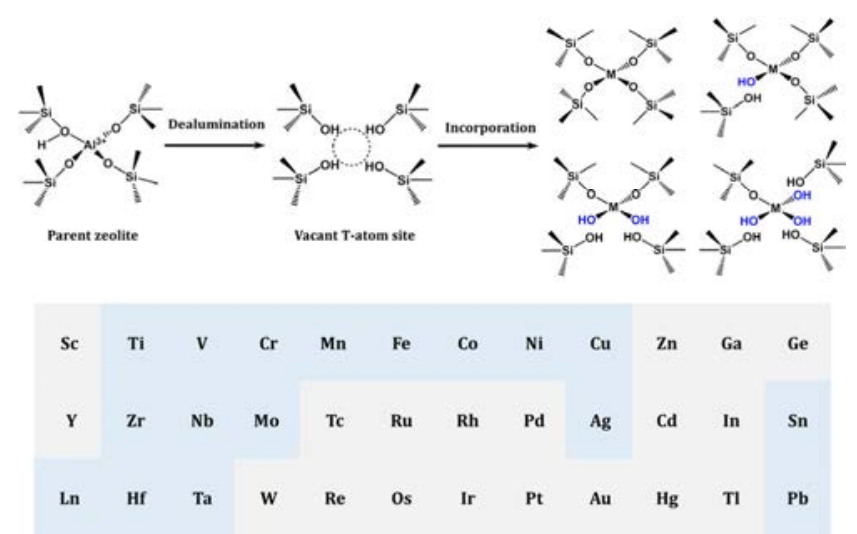

Fig. 3. Schematic of metallosilicate zeolites by post-synthesis strategy and the types of metal ions in zeolite framework.
Nevertheless, the combination of different analytical techniques is necessary to obtain the accurate and comprehensive information on the coordinatively unsaturated sites. Herein, we aim to show the characterization of the coordinatively unsaturated sites by parallel techniques such as vibrational (IR and Raman), electronic (UV-vis and XPS) and spin resonance (EPR and solid state NMR) spectroscopy. The X-ray absorption spectroscopy (XAS) is discussed at the last due to its irreplaceable role in the characterization of coordinating states and relatively short history compared with other techniques.

\subsection{Vibrational spectroscopy}

It is known that infrared spectroscopy, mostly on the basis of absorption spectroscopy, involves the interaction of infrared radiation with a certain material. Since infrared absorption spectrum is generated from the polarity within a molecule, those symmetrical molecules without polarity are generally not applicable for infrared spectroscopy analyses. Raman spectroscopy widely employed to detect the vibrational, rotational, and other low-frequency modes in a material system. Raman spectroscopy is generated by the electric quadrupole moment or the magnetic dipole moment transition, making it especially suitable in characterizing the symmetrical molecules without polarity. For a given chemical bond, the infrared absorption frequency should be equal to the Raman shift, both of which demonstrate the energy of the first vibrational level. That is, the active infrared absorption wavenumbers and Raman shifts should be theoretically the same, giving the molecular structure information in the infrared region.

\subsubsection{Fourier transform infrared spectroscopy (FTIR)}

For detecting the signal of heteroatoms in the framework of zeolites, a typical FTIR tool is employed. With heteroatoms incorporated into the zeolite framework, the infrared antisymmetric stretching vibration frequency of the Si-O-Al structure in the zeolite framework and the symmetric stretching vibration frequency will be influenced. For instance, after the introduction of heteroatom $\mathrm{B}$, the anti-symmetric stretching vibration frequency $\left(1050-1150 \mathrm{~cm}^{-1}\right)$ and the symmetric stretching vibration frequency $\left(750-820 \mathrm{~cm}^{-1}\right)$ of $\mathrm{Si}-\mathrm{O}-\mathrm{Al}$ structure in the framework of the zeolites both show the blue shift toward higher frequencies. Upon the introduction of heteroatoms such as $\mathrm{Ti}$ and $\mathrm{Fe}$, the stretching vibrations of framework are redshifted to lower frequencies. This can be well explained by the equation of vibration frequency $(v=\sqrt{k / \mu} / 2 \pi)$ where the vibration frequency is determined by the force constant of the bond. If $\mathrm{M}-\mathrm{O}$ bond is shorter and stronger than the $\mathrm{Al}-\mathrm{O}$ bond (for example in the case of $\mathrm{B}-\mathrm{O}$ ), the force constant will be larger and therefore lead to higher vibration frequency, and vice versa. In addition to the shifts in framework vibrations, the introduction of framework heteroatoms was proposed to bring about new stretching vibration for Si-O-M or Al-O-M (M = Ti, Sn, Zr and Fe) at $960 \mathrm{~cm}^{-1}$ [88]. This band was once considered as the direct evidence of heteroatom incorporation into the zeolite framework. However, Shen et al. [89] disclosed the absence of IR absorption peak of $960 \mathrm{~cm}^{-1}$ 
with low content of heteroatoms and high zeolite crystallinity. Recently, Nikolakis et al. confirmed that the IR absorption peak of the Sn-beta zeolite at $\sim 960 \mathrm{~cm}^{-1}$ was not created by the $\mathrm{Si}-\mathrm{O}-\mathrm{Sn}$ vibration but originated from the isolated internal $\mathrm{Si}-\mathrm{OH}$ species through the combination of experimental approaches and theoretical calculations [90]. This sounds more reasonable and the presence of isolated $\mathrm{Si}-\mathrm{OH}$ is accompanied by the formation of heteroatoms in so-called open configurations, i.e. $\mathrm{M}[\mathrm{OSi}]_{3}[\mathrm{OH}], \mathrm{M}[\mathrm{OSi}]_{2}[\mathrm{OH}]_{2}$ and $\mathrm{M}[\mathrm{OSi}][\mathrm{OH}]_{3}$ (Fig. 3).

Ivanova et al. [91] employed FTIR spectroscopy with $\mathrm{CO}$ as a probe (low temperature adsorption) to determine the open and closed $\mathrm{Zr}$ sites in Zr-beta zeolite directly. It was proposed that $\mathrm{Zr}$ (IV) Lewis acid sites in Zr-beta were represented by isolated framework $\mathrm{Zr}$ atoms in the tetrahedral positions linked with four (closed site) and three (open site) Si atoms from FTIR spectra (Fig. 4(a)) and DFT calculations (Fig. 4(b)).

The extra-framework TMIs have limited impacts on the vibrations of zeolite framework atoms and the direct characterization of TMIs by FTIR spectroscopy with probe molecules such as NO and CO is preferred. The properties of TMIs, especially their valence and coordination states, can be monitored by the changes in the vibrational frequencies and intensities of characteristic FTIR bands, which are related to $\sigma$ donation from $\mathrm{CO}$ to TMIs (increasing $v_{\mathrm{CO}}$ ) and $\pi$ back-donation from TMIS to

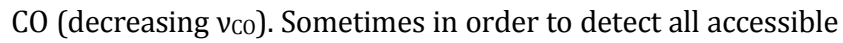
TMIs and the possible adsorption of more than one molecule at one site, the experiments are performed at the temperature of liquid nitrogen or slightly higher $(\sim 100 \mathrm{~K})$. For example, the extraframework cupric and cuprous ions can be well distinguished by the means of FTIR spectroscopy with CO adsorption. Since the affinity of $\mathrm{Cu}^{2+}$ toward $\mathrm{CO}$ is negligible at room temperature or higher, the $\mathrm{CO}$ probe dominantly bounds to $\mathrm{Cu}^{+}$ and the FTIR spectra of $\mathrm{CO}$ adsorption on $\mathrm{Cu}^{+}$in various zeolites are quite similar $[19,35,92,93]$. Typically, there is a domi- (a)

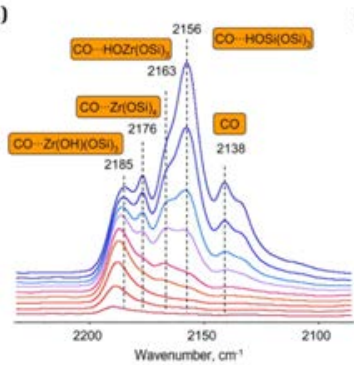

(c)

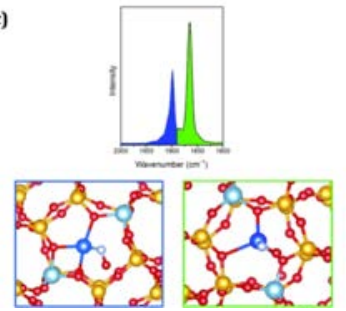

(b)
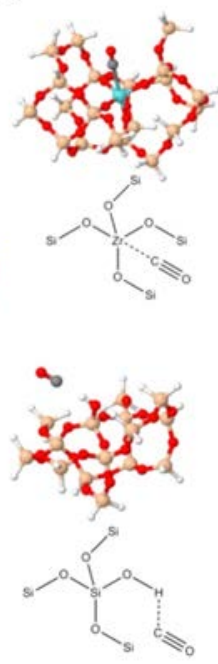
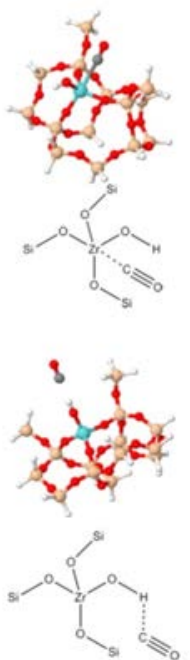

Fig. 4. (a) FTIR spectra of $\mathrm{CO}$ adsorption on $\mathrm{Zr}$-BEA with increasing $\mathrm{CO}$ coverage; (b) Optimized structures of $\mathrm{CO}$ adsorption on the closed and open $\mathrm{Zr}$ sites as well as $\mathrm{OH}$ groups in $\mathrm{Zr}$-BEA, reproduced from Ref. [91] with permission; (c) FTIR spectra of NO adsorption on $\mathrm{Cu}-\mathrm{CHA}$ under different finite temperatures with the corresponding coordination configurations of $\mathrm{Cu}$ sites, reproduced from Ref. [98] with permission. nating band centered at $2154 \mathrm{~cm}^{-1}$ with highly symmetric absorption feature at low CO partial pressures. After the saturation of this IR band, its position apparently shifts toward higher frequency, i.e. a new IR band appears at $2178 \mathrm{~cm}^{-1}$ due to the formation of new dicarbonyl species on $\mathrm{Cu}^{+}$ions. The low-intensity IR bands due to $\mathrm{Cu}^{+}$-bound dicarbonyls and $\mathrm{Cu}^{2+}$-adsorbed $\mathrm{CO}$ are only observed in the presence of gas-phase $\mathrm{CO}$ and they disappear upon evacuation. According to these observations, the IR bands in the range of 2154-2160 $\mathrm{cm}^{-1}$ are undoubtedly ascribed to the $v_{\mathrm{C}=0}$ stretching vibrations of $\mathrm{CO}$ bound to $\mathrm{Cu}^{+}$ions that are located in zeolite cavities and pores [92]. The $\mathrm{CO}$ adsorption at low temperature can also detect and distinguish other TMIs even at different positions. In the case of cobalt [94], $\mathrm{Co}^{2+}$ ion located at exchange positions is monitored by a band at $2204 \mathrm{~cm}^{-1}$ assigned to $\mathrm{Co}^{2+}-\mathrm{CO}$ while $\mathrm{Co}^{2+}$ in oxide-like clusters $\left(\mathrm{CoO}_{x}\right)$ shows an adjacent carbonyl band at $\sim 2194 \mathrm{~cm}^{-1}$.

NO has been proven to be a sensitive molecular probe for extra-framework TMIs with different valence states complementary to CO. The coordination of NO to a TMI results in the formation of nitrosyl species, which shows a wide spectral range. It should be noted that the spectra may show the presence of mono-, di-, and even tri-nitrosyl species associated with TMIs [95]. As a result, this method has been testified by rich literatures reporting IR spectra of TMI-nitrosyl species in zeolites and it has been achieved by the well affinity of NO toward TMIs forming the above-mentioned $\mathrm{Me}^{x+}(\mathrm{NO})_{n}$ nitrosyls $(n=1$, $2,3)$ [96]. A typical process of this method is to change the NO equilibrium pressure and a full range of coverage can be explored. For example, NO is often used to investigate the oxidation state of copper species since it is able to coordinate with both $\mathrm{Cu}^{+}$and $\mathrm{Cu}^{2+}$ ions. Typically, vibrational bands assigned to NO molecules adsorbed on both $\mathrm{Cu}^{2+}\left(1948\right.$ and $\left.1914 \mathrm{~cm}^{-1}\right)$ and $\mathrm{Cu}^{+}\left(1810\right.$ and $\left.1780 \mathrm{~cm}^{-1}\right)$ sites could be seen in the FTIR spectra of NO adsorption [97]. FTIR spectra of NO adsorption can be even employed to identify isolated $\mathrm{Cu}^{\mathrm{II}}$ species in Cu-SSZ-13 zeolite with different configurations [98]. Typically, the temperature-induced movement of $\mathrm{Cu}$ atoms between two different configurations, i.e. one in the center of the six-membered ring and bonded to two activated 0 atoms while the other bonded to three activated $\mathrm{O}$ atoms, is revealed (Fig. $4(\mathrm{c})$ ), in good agreement with the analysis from the molecular dynamics trajectory. For Co-zeolites, the bands at around 1810 and $1890 \mathrm{~cm}^{-1}$ are assigned to dinitrosyl species absorbed on $\mathrm{Co}^{2+}$ with asymmetric and symmetric stretching vibrations, respectively, while the mononitrosyl species give the bands at around $1930 \mathrm{~cm}^{-1}$. With increasing NO pressure through the 'titration' method, the intensity ratio of the dinitrosyl species to mononitrosyl species increases distinctly, indicating that mononitrosyl species are the precursors for dinitrosyl species [99].

\subsubsection{Raman spectroscopy}

The shift between the frequency of Raman scattered light and that of Rayleigh scattered light is stable with the changing frequencies of incident light, and it is determined by the vibrations and rotations of the samples. On the other hand, the in- 
tensity of Raman spectrum can be directly related to the intensity of incident light and the concentration of sample. Angell first used Raman spectroscopy to study the zeolite framework as early as 1973 [97,100]. The strongest Raman band appears at $300-600 \mathrm{~cm}^{-1}$ due to the vibration of T-O-T (T indicates the central atom in the tetrahedra building block of zeolite), which can be employed to determine the ratio of Si/Al. Generally, Raman spectroscopy is not suitable for characterizing TMIs in zeolites since the intensity of fluorescence signal might be millions of times stronger than that of Raman signal. This problem can be addressed by replacing of visible laser by ultraviolet laser. Li et al. [101] characterized TS-1 using UV laser with the wavelength of $244 \mathrm{~nm}$ and got the direct evidence of framework Ti atom. Xiao et al. [102] observed the Raman shift of $1100 \mathrm{~cm}^{-1}$ in Fe-zeolites, which was assigned to the antisymmetric stretching vibration of $\mathrm{Fe}-\mathrm{O}-\mathrm{Si}$ species and its intensity decreased with the increasing content of $\mathrm{Fe}$. In addition, Raman shifts at around 380-540 and 725-885 $\mathrm{cm}^{-1}$ were observed due to the symmetric and antisymmetric stretching vibration of the Fe-O-Fe species, respectively. In brief, the UV laser Raman spectroscopy is a powerful and smart tool for the analysis of TMIs in zeolite framework.

\subsection{Electronic spectroscopy}

For the electronic spectroscopy, UV-vis diffuse reflection spectroscopy (UV-vis-DRS) and X-ray photoelectron spectroscopy (XPS) will be included. The similarity of UV-vis-DRS and XPS is that both are radiated by the artificial light and the inner-shell electrons are excited. Their apparent difference lies in the light source, i.e. ultraviolet-visible light for UV-vis-DRS and $\mathrm{X}$-ray for XPS. Due to the different energy value of light source, the electrons can escape from the atoms as free electrons in XPS while the electrons are only excited to a higher energy level but still constrained by the nuclei in UV-vis-DRS.

\subsection{1. $U V$-vis-DRS}

The charge transfers and $d-d$ electron transitions of TMIs can be characterized by UV-vis-DRS. For heteroatoms incorporated into zeolite framework, their chemical environment is changed and the charge transfer will occur in connection with heteroatoms, resulting in corresponding absorption bands. Experimentally, most of the zeolites with framework heteroatoms such as $\mathrm{Ti}, \mathrm{Sn}, \mathrm{Zr}$, and Fe exhibit sharp absorption bands in the range of 43500-52600 $\mathrm{cm}^{-1}$ originated from the framework tetra-coordinated heteroatoms. While the broad absorption bands in the range of $20800-33300 \mathrm{~cm}^{-1}$ are generally originated from the electron transition of extra-framework cations. In this context, UV-vis-DRS can be used as a simple but effective technique to identify the successful incorporation of heteroatoms into zeolite framework. For example, framework tetra-coordinated Sn(IV) in Sn-beta zeolite shows UV absorption bands in the $45500-49300 \mathrm{~cm}^{-1}$ range, which are assigned to the transition of electron towards the unoccupied orbitals of isolated Sn(IV) from the surrounding O-atoms (ligand to metal charge transfer, LMCT). In contrast, octa-coordinated Sn species in the forms of small $\mathrm{SnO}_{2}$ particles show exclusive absorp- tion bands at 33300-40300 $\mathrm{cm}^{-1}$ [103]. In the case of Ti-zeolites, the isolated tetra-coordinated $\mathrm{Ti}$ atoms such as $\mathrm{Ti}[\mathrm{SiO}]_{4}$ and $\mathrm{Ti}[\mathrm{SiO}]_{3}[\mathrm{OH}]$ in zeolite framework exhibit the charge transfer from ligand $\mathrm{O}$ to the unoccupied orbits of $\mathrm{Ti}$ centers i.e. LMCT resulting in the absorption bands at around $47600 \mathrm{~cm}^{-1}$ (the band position is also related to the zeolite topology with $\pm 2000 \mathrm{~cm}^{-1}$ displacement). The presence of isolated extra-framework hexa-coordinated Ti species in Ti-zeolites (at relatively high Ti loadings) is characterized by the broad absorption bands in the range of $34500-37000 \mathrm{~cm}^{-1}$. It should be emphasized that since the tetra-coordinated Ti species can coordinate with $\mathrm{H}_{2} \mathrm{O}$ to form $\mathrm{Ti}$ species $\mathrm{Ti}_{2}\left(\mathrm{H}_{2} \mathrm{O}\right)_{x} \mathrm{O}_{4}(x=1$ or 2$)$ with high coordination numbers, the red shifts in their UV-vis-DRS are always observed [104]. Corma et al. [105] believed that the absorption peak at $33300-43500 \mathrm{~cm}^{-1}$ was related to the isolated or low-polymerized titanium species (including Ti-O-Ti bond) and, accordingly, there was no extra-framework Ti in the as-synthesized Ti-Y zeolite. To address this controversial issue, in situ UV-vis-DRS of samples under strictly dehydrated and hydrated conditions are preferred.

UV-vis-DRS can also be used to investigate the nature of the extra-framework coordinatively unsaturated TMIs in zeolite matrix. For isolated $\mathrm{Cu}^{2+}$ sites in zeolites, the UV-vis-DRS demonstrated an intense, broad and unresolved CT band in the $40000-48000 \mathrm{~cm}^{-1}$ region and weak $d-d$ transitions in the region of $9000-15,000 \mathrm{~cm}^{-1}$. In contrast, $\mathrm{Cu}^{+}$has a fully occupied $3 d$ orbitals and, therefore, there are no $d-d$ transitions. Concerning the coordination chemistry of $\mathrm{Cu}^{2+}$ in zeolites, the $d-d$ transition and CT bands are influenced by zeolite framework to some extent, and the different $d-d$ components are only partially resolved. In the case of Cu-SSZ-13 zeolite, the $d-d$ transition band occurs at around $12000 \mathrm{~cm}^{-1}$ and CT $(\mathrm{O}-\mathrm{Cu})$ band at $47500 \mathrm{~cm}^{-1}$. While for $\mathrm{Cu}-\mathrm{Y}$, the $d-d$ transition of $\mathrm{Cu}^{2+}$ is broadened by additional absorption edges below $10000 \mathrm{~cm}^{-1}$ and above $15000 \mathrm{~cm}^{-1}$. In addition to the isolated $\mathrm{Cu}$ sites, there are recently widespread concerns about a new band found at around $22700 \mathrm{~cm}^{-1}$ due to CT band of mono-O-oxo [Cu-O-Cu ${ }^{2+}$ species that are proposed to be the key sites for methane activation $[106,107]$. Other TMIs in zeolite matrix can also be monitored by means of UV-vis-DRS. For example, Bellmann et al. investigated the UV-vis-DRS of Co-ZSM-5 prepared via a simple WIE process $[22,94]$. The spectrum was dominated by an intense band around $29000 \mathrm{~cm}^{-1}$ attributed to a LMCT transition from $\mathrm{O}$ to $\mathrm{Co}^{3+}$ ions and a weak band at around $20800 \mathrm{~cm}^{-1}$ attributed to octa-coordinated $\mathrm{Co}^{2+}$ species could also be observed.

\subsection{2. $X P S$}

XPS is based on exciting the samples in ultra-high vacuum by mono-energetic soft X-rays ( $\mathrm{Mg} K_{\alpha}$ at $1253.6 \mathrm{eV}$ or Al $K_{\alpha}$ at $1486.6 \mathrm{eV}$ ) and analyzing the energy states of the detected electrons. The spectrum is recorded by plotting the number of detected electrons per energy interval versus their corresponding kinetic energy. Generally, XPS is employed to determine the valence state of specific element and herein we will briefly elucidate its applications with Co-zeolites, $\mathrm{Cu}$-zeolite and Sn-zeolites as examples. 
For cobalt, the $2 p$ transitions are usually measured. Upon ionization treatment, the $2 p$ level will split into $2 p_{1 / 2}$ and $2 p_{3 / 2}$ with the spin-orbit coupling ratio of $1 / 2 \mathrm{Co}^{2+}$ of ion-exchanged zeolites, e.g. in Co-ZSM-5, is characterized by a $2 p_{3 / 2}$ peak at around $782.0 \mathrm{eV}$ with an intense shoulder at 787-788 eV. Upon calcination, $\mathrm{Co}^{3+}$ is formed at the expense of the $\mathrm{Co}^{2+}$, the main $2 p_{3 / 2}$ peak shifts to lower energy value and its shoulder decreases in intensity [15]. For copper, two characteristic binding energy values at around 935.5 and $944.3 \mathrm{eV}$ can be assigned to the $\mathrm{Cu}^{2+}$ ion together with its shake-up satellite peak of $\mathrm{Cu} 2 p_{3 / 2}$ [108]. The peak at around $933 \mathrm{eV}$ brought by $\mathrm{Cu}^{+}$implies its existence and the percentages of $\mathrm{Cu}^{2+} / \mathrm{Cu}^{+}$in the near surface region can be quantified by comparing the corresponding peak areas. The presence of $\mathrm{Cu}^{0}$, which is not expected in $\mathrm{Cu}$-zeolites, cannot be easily distinguished from $\mathrm{Cu}^{+}$and Auger analysis is recommneded. For tin, binding energy values at around 487.3 and $495.7 \mathrm{eV}$ are observed in zeolite framework, which is generally attributed to the $3 d_{5 / 2}$ and $3 d_{3 / 2}$ photoelectrons of Sn (IV) in tetrahedral coordination. Considering that bulk $\mathrm{SnO}_{2}$ particles display the binding energy values at $486.0\left(3 d_{5 / 2}\right)$ and $494.4 \mathrm{eV}\left(3 d_{3 / 2}\right)$, the electron transfer from $\mathrm{Sn}$ centers to zeolite framework can be clearly illustrated [14]

\subsection{Spin resonance spectroscopy}

Nuclear magnetic resonance (NMR) is a physical phenomenon from the absorption and reemitting of electromagnetic radiation by nuclei in a magnetic field. Solid-state NMR spectroscopy is widely used to determine the fine structure and coordination environment of various materials. Electron paramagnetic resonance (EPR), sometimes called electron spin resonance (ESR), spectroscopy is an efficient means for studying the materials with unpaired electrons, which is particularly useful for metal complexes or organic radicals. The basic concept of EPR is analogous to that of NMR, but the electron spins are excited in EPR instead of nuclei spins in NMR. In both EPR and NMR experiments, samples are placed in high magnetic fields and irradiated with a radiofrequency source. The $g$ factor obtained in ESR spectroscopy corresponds to the chemical shift $(\delta)$ in NMR.

\subsubsection{Solid-state NMR}

Solid-state NMR spectroscopy has been employed in the characterization of zeolites for decades. This technique can provide detailed structural information of the zeolite framework and is often used in combination with XRD that detects the long-range ordered structure of the skeleton. For example, ${ }^{29} \mathrm{Si}$ and ${ }^{27} \mathrm{Al}$ NMR can provide information about the coordination arrangements of $\mathrm{Si}$ and $\mathrm{Al}$ in the zeolite framework and the location of the non-equivalent $\mathrm{SiO}_{4}$ tetrahedron and $\mathrm{AlO}_{4}$ tetrahedron in the structure. Since the atomic radius of framework heteroatom is different from that of $\mathrm{Si}$ or $\mathrm{Al}$, the length of $\mathrm{M}-\mathrm{O}$ bond differs from that of $\mathrm{Si}(\mathrm{Al})-\mathrm{O}$ bond and leads to the distortion of tetrahedral structure. In such a way, the chemical environment around $\mathrm{Si}$ is changed, resulting in the changes in ${ }^{29} \mathrm{Si}$ NMR spectrum. A new shoulder signal should appear in the higher field than that of original $\mathrm{Si}(4 \mathrm{Si})$, which can be used as an indirect evidence for the incorporation of heteroatoms into zeolite framework. In addition, ${ }^{1} \mathrm{H}$ NMR can be employed to monitor the incorporation of framework heteroatoms via post-synthesis modifications. Typically, the extraframework $\mathrm{Al}-\mathrm{OH}$ (2.5 ppm) and Si-OH-Al (3.9 ppm) signals disappear after the complete dealumination of beta zeolite, while the signal at $1.5 \mathrm{ppm}$ due to $\mathrm{Si}-\mathrm{OH}$ at framework defect is significantly promoted, accompanied by the formation of associated hydroxyls (2.7 ppm). With the introduction of Ti atoms, the intensity of $\mathrm{Si}-\mathrm{OH}$ and associated hydroxyls species decrease significantly, indicating the condensation between $\mathrm{Ti}$ and $\mathrm{Si}-\mathrm{OH}$ species and the subsequent incorporation of $\mathrm{Ti}$ atoms into zeolite framework.

In theory, the coordination information of TMIs or main-group cations in zeolite matrix can be characterized by NMR. However, since most of these cations belong to quaternary nuclei and their loadings are relatively low, the NMR signals are usually very weak and cannot meet the requirements of spectral analysis. In the literature, the coordination environment of $\mathrm{Sn}$ in Sn-zeolite has been extensively investigated by means of NMR. Bulk $\mathrm{SnO}_{2}$ is known to give ${ }^{119} \mathrm{Sn}$ NMR signal at around $-604 \mathrm{ppm}$, corresponding to Sn species in octahedral coordination [109]. The tetrahedral Sn species in zeolite framework, for example in Sn-beta, are reported to give a resonance signal at -443 ppm [110]. Davis et al. [109] further reported two resonance signals at -420 and -443 ppm in dehydrated Sn-zeolite: the former being ascribed to tetrahedral Sn in open arrangement and the latter to tetrahedral $\mathrm{Sn}$ in close arrangement. Upon hydration, these tetrahedral Sn centers would coordinate two additional water molecules to become octahedral and give signals at -685 and $-700 \mathrm{ppm}$, respectively.

Due to the low natural abundance of the ${ }^{119} \mathrm{Sn}$ isotope, enriched ${ }^{119} \mathrm{Sn}$ sample should be prepared and/or long acquisition time is needed in ${ }^{119} \mathrm{Sn}$ NMR experiments. To solve the problem, dynamic nuclear polarization (DNP) NMR technique was developed for studying Sn-beta zeolite containing 2 wt\% Sn of natural abundance [111]. By using appropriate radical/solvent combination, the acquisition time could be reduced more than two orders of magnitude, making DNP NMR a method of choice for chemical structure determination (Fig. 5(a)). Another interesting work from Ivanova et al. [112] demonstrated the fast characterization of Sn sites in zeolites via ${ }^{119}$ Sn Carr-Purcell-Meiboom-Gill (CPMG) MAS NMR. Compared to conventional methods, the experimental time can be decreased by a factor of 5-40 and 3 orders of magnitude, through the tuning of the CPMG echo-train sequence, for hydrated and dehydrated Sn-BEA samples, respectively. In the work that followed, they succeeded in the observation of $\mathrm{Sn}$ in different T-sites of Sn-BEA by one- (Fig. 5(b)) and two-dimensional (Fig. 5(c)) ${ }^{119}$ Sn MAS NMR spectroscopy.

\subsection{2. $E P R$}

EPR is especially suitable for studying TMIs with unpaired electrons. Slinkin et al. [114] has performed a systematic study on the coordination environment of TMIs in zeolites by means of EPR, where many of the cations can give rise to characteristic 
(a)

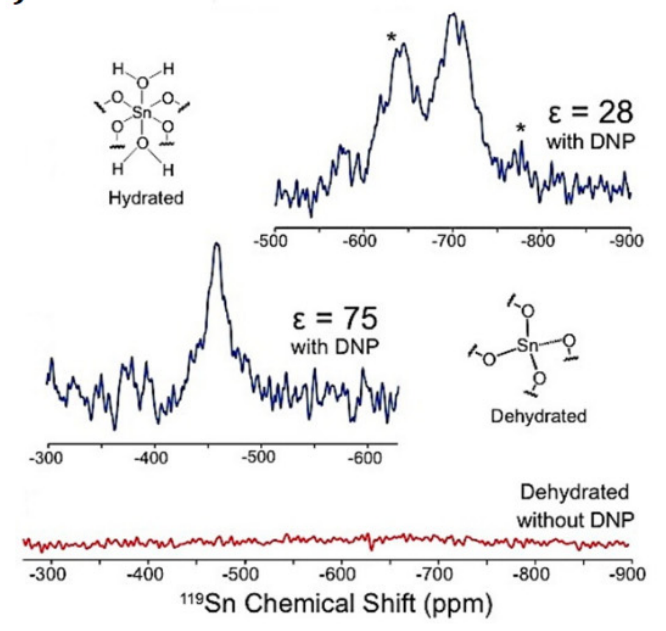

(b)

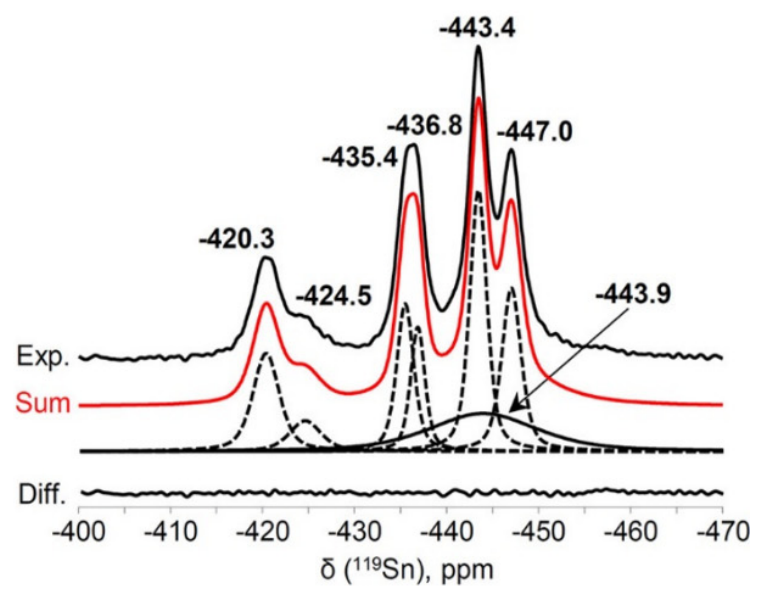

(c)
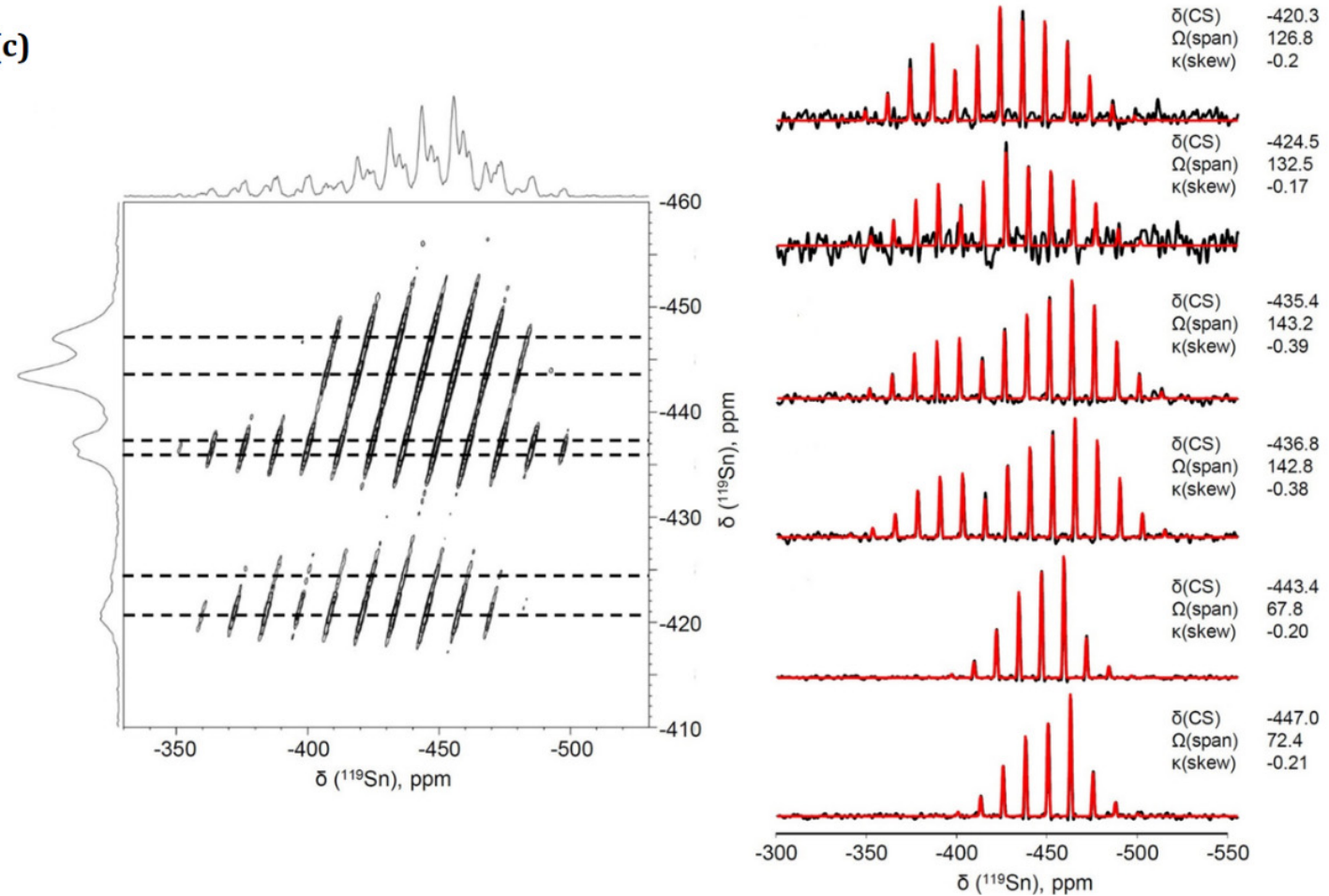

Fig. 5. (a) ${ }^{119}$ Sn NMR spectra of hydrated and dehydrated Sn-BEA zeolite (natural abundance) with and without DNP, reproduced from Ref. [111] with permission. * denotes spinning sidebands; (b) ${ }^{119}$ Sn DP-CPMG MAS NMR spectrum of dehydrated Sn-BEA ( $\tau$ cPMG $=7$ ms, Necho $=250$ ), from Ref. [113] with permission; (c) ${ }^{119}$ Sn 2D MAT-CPMG MAS NMR spectrum of Sn-BEA with sideband slices for corresponding lines, reproduced from Ref. [113] with permission.

ESR signals. However, the spin-lattice relaxation will hinder the observation of EPR signals, especially those from octahedral ions. Generally, EPR spectra are reasonably resolved with relatively low loadings of TMIs in zeolites (for example $<5$ wt\%). At higher TMIs loading, less energetically favorable sites will be occupied and TMIs may exist in the form of mixtures containing mono-, di-, and oligonuclear clusters or even up to chains of TMIs. In this context, some of the paramagnetic TMIs will become EPR-silent due to antiferromagnetic coupling and dipolar broadening. Herein, we will present some examples of detecting TMIs ( $\mathrm{Co}, \mathrm{Cu}$ and $\mathrm{Fe}$ ) in zeolite by means of EPR.

For the $\mathrm{Co}^{3+}$ in zeolite, the distortion of the crystal-field symmetry lifts the degeneracy of the $5 \mathrm{E}$ state, and the second-order spin-orbit coupling leaves an $m_{\mathrm{s}}=0$ spin state as the zero-field ground state [115]. Consequently, the $g=5.5$ and $g=2.05$ of $\mathrm{Co}-\mathrm{A}$ are attributed to $\mathrm{Co}^{2+}$ in an elongated tetrahedral environment, while the other EPR parameters $\left(g_{/ /}=3.3, g_{\perp}\right.$ $=2.1, g_{\text {average }}=2.2$ ) are attributed to a compressed tetrahedral environment.

Zamadics et al. [116] observed the exclusive EPR signal ( $g / /$ $=2.381, A=143 \mathrm{G}$ ) in hydrated Cu-SAPO-34 and assigned it to $\mathrm{Cu}^{2+}$ located in site I as a complex $\mathrm{Cu}(\mathrm{O})_{3}\left(\mathrm{H}_{2} \mathrm{O}\right)_{3}$. Similar EPR signals of $\mathrm{Cu}(\mathrm{O})_{3}\left(\mathrm{H}_{2} \mathrm{O}\right)_{3}$ species were reported for $\mathrm{Cu}-\mathrm{SSZ}-13$ samples, such as $g_{/ /}=2.39$ with $A=111 \mathrm{G}$ and $g_{/ /}=2.394$ with $A$ 
$=131 \mathrm{G}$ [117]. Considering that isolated $\mathrm{Cu}^{2+}$ species can migrate from one site to another upon thermal treatment, the dehydrated samples always contain more types of $\mathrm{Cu}$ species than the hydrated samples [116]. In addition, Herman et al. [118] confirmed that EPR signals of $\mathrm{Cu}^{2+}$ with trigonal environment varied with different $\mathrm{Cu}$ loading and different evacuation time during dehydration process, and the changing signals from $g_{/ /}=2.36$ with $A=125 \mathrm{G}$ to $g / /=2.38$ with $A=110 \mathrm{G}$ were recorded.

For Fe-zeolite samples, the formation of a $\mathrm{Fe}^{3+} \mathrm{O}^{--}$radical was tentatively suggested according to the coexistence of EPR signals at $g=6.4$ and 2.018, assigned to $\mathrm{Fe}^{3+}$ and an $0^{--}$radical moiety, respectively [119]. However, if $\mathrm{Fe}^{3+} \mathrm{O}^{--}$core does exist, $S=5 / 2$ of $\mathrm{Fe}^{3+}$ should couple antiferromagnetically with the radical $S=1 / 2$, resulting in an overall $S=2$ ground state, which could not be detected by X-band EPR spectroscopy even at liquid- $\mathrm{N}_{2}$ temperature.

\subsection{X-ray absorption spectroscopy (XAS)}

$\mathrm{XAS}$, commonly with synchrotron radiation, is widely employed to investigate the geometric and electronic structure of a target atom in material. In XAS, the core electrons are excited from the energy level of ground state to higher energy levels and the ejected electrons are scattered from surrounding atoms. The two or three closest shells of neighboring atoms surrounding the target atom can make contributions to the XAS signals, and in this context, XAS represents a local structure probe. Since XAS determines the pre-, near- and extended-edge structures, it is commonly subdivided into pre-edge X-ray absorption (PEXA), X-ray absorption near-edge structures (XANES) and extended X-ray absorption fine structure (EXAFS). In the energy region extending from about 0 to $50 \mathrm{eV}$ above binding energy $\left(E_{\mathrm{b}}\right)$, the electrons are multiply scattered among neighboring atoms, which produces the XANES spectrum. When hv is about 50 to $1000 \mathrm{eV}$ above $E_{\mathrm{b}}$, electrons are ejected from the absorber, and then leave the vicinity of the absorber. The EXAFS spectrum is due to interferences between kinetic energies given by outgoing and backscattered photoelectrons, which modulates the atomic absorption coefficient. The pre-, near- and extended-edge structures provide extremely detailed information on the local structure of heteroatoms and on the number and distance of neighboring atoms. Theoretical interpretation of spectra has been achieved to very high level of accordance with experiment, which is most useful in the interpretation of experimental spectra that have no counterpart in the database. However, the XAS analysis only gives the average information of the atomic structure of the sample area tested, and it is not effective in distinguishing adjacent nuclei (such as $\mathrm{Si}$ and $\mathrm{Al}$ ), which limits its applications to some extent.

EXAFS method allows us to obtain the direct structural information of coordinatively unsaturated metal centers. The main structural parameters obtained through EXAFS contain interatomic distances (R) and coordination numbers (CN) of metal centers. Furthermore, valence of the metal and the existence of clusters can be auxiliarily confirmed if there are characteristic interatomic distances of M-M.

For a most simple example, Gabrienko et al. [120] obtained the parameters of $\mathrm{Zn}^{2+} / \mathrm{H}-\mathrm{BEA}$ sample: $\mathrm{R}_{\mathrm{Zn}-0} \approx 1.96-2.02 \AA$, CN $=3.8$, and no peak of $\mathrm{Zn}-\mathrm{O}-\mathrm{Zn}$ was found (Fig. $6(\mathrm{a})$ ). This result showed that there were only isolated $\mathrm{Zn}$ ions in the sample and it had a medium coordination number. Sano et al. [121] concluded that peaks found in hydrated $\mathrm{Ni} / \mathrm{Y}$ zeolite was attributed to coordinated oxygen atoms with the coordination number of 5.9 and Ni-O distance of $2.06 \AA$ using EXAFS. However, dehydration caused little change in the position of the peak along with a dramatic decrease in its intensity with the coordination number of 3.6 and Ni-O distance of $2.05 \AA$. The experimental evidence showed that nickel ions in dehydrated nickel Y zeolite existed separately with unsaturated oxygen coordination. Bordiga et al. [122] got the precise Fe-O distance of different Fe-O samples for $1.85 \AA$ within error of $\pm 0.01 \AA$. The energy of the absorption band and the $\mathrm{Cu}-\mathrm{Cu}$ distance of $2.87 \AA$ obtained by EXAFS are used to rule out the presence of a peroxo moiety, which typically has longer $\mathrm{Cu}-\mathrm{Cu}$ distances. Since EXAFS shows (a)

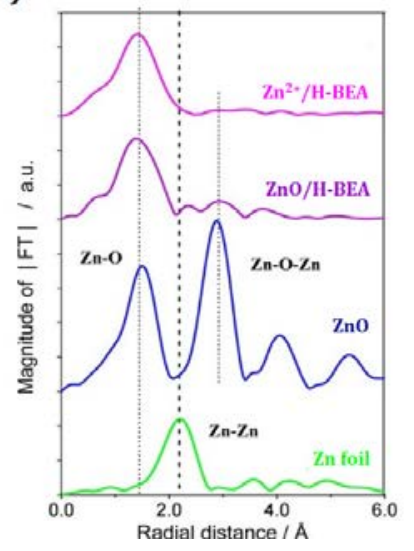

(b)

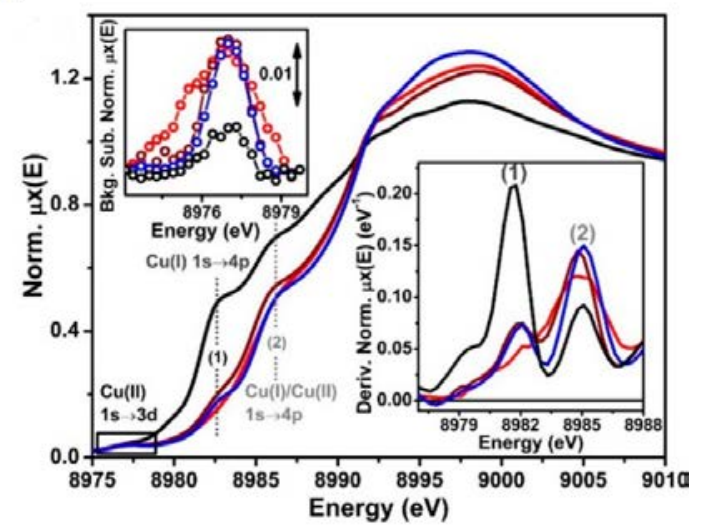

Fig. 6. (a) Radial distribution function curves of $\mathrm{Zn}^{2+} / \mathrm{H}-\mathrm{BEA}, \mathrm{ZnO} / \mathrm{H}-\mathrm{BEA}, \mathrm{ZnO}$ bulk oxide and $\mathrm{Zn}$ foil reference, reproduced from Ref. [120] with permission; (b) $\mathrm{Cu} K$-edge XANES spectra (main panel), background subtracted $\mathrm{Cu}^{\mathrm{II}} 1 s \rightarrow 3 d$ pre-edge peaks (left inset) and first derivative of the XANES spectra in the rising-edge region (right inset) of the Cu-CHA with different pretreatments, reproduced from Ref. [126] with permission. 
the averaged data for all $\mathrm{Cu}$ sites in the tested area of Cu-ZSM-5, it is not sensitive enough to probe these active $\mathrm{Cu}$ sites [123]. EXAFS enables the identification of the Sn atoms and their neighboring atoms, and, therefore, the distinguishment among hexa-coordinated $\mathrm{SnO}_{2}$, tetra-coordinated framework $\mathrm{Sn}$ and the hydrated Sn species can be achieved. The EXAFS analysis shows that Sn-O distance in the tetrahedral coordinated framework $S n$ of $S n$-beta is shorter $(1.91 \AA$ ) than in the octahedral Sn oxide $\mathrm{SnO}_{2}$ (2.05 $\AA$ ). Besides, the spectrum of $\mathrm{SnO}_{2}$ sample shows a peak between 2.5 to $4 \AA$ associated with $\mathrm{Sn}-\mathrm{Sn}$ scattering, which should be absent in a pure Sn-beta [124].

However, EXAFS has its limitation since it can only give the average information and structure of the sample plane of multi-absorption centers. And it cannot give out the micro-changes of the structure. XANES shows better SNR (Signal to Noise Ratio) than EXAFS with the level of $10^{2}$, lower dependent of temperature and shorter acquisition time. Hence, it can be used in the high-temperature operando or the time-resolved experiments. Tetrahedral coordination $\mathrm{Ti}^{4+}$ ion has strong XANES characteristic peak at $4969 \mathrm{eV}$, which can be used to distinguish zeolite framework Ti atoms. The information about coordination number and ion intensity of the corresponding surface of $\mathrm{Ti}^{4+}$ can be given by the intensity and position of the characteristic peak before the $\mathrm{K}$ absorption edge. Tetrahedral coordinated $\mathrm{Ti}^{4+}$ has the highest intensity, octahedral hexa-coordinated $\mathrm{Ti}^{4+}$ intensity is the lowest, and the intensity of penta-coordinated $\mathrm{Ti}^{4+}$ is between them. Coordination state information of different $\mathrm{Ti}^{4+}$ ions can be obtained through normalization treatment [125]. The Co K-edge XANES spectra of as-synthesized Co-substituted molecular sieves have the pre-edge feature (denoted as the $1 s \rightarrow 3 d$ transition) around $7710 \mathrm{eV}$, which is typical for $\mathrm{Co}^{2+}$ in tetrahedral coordination [15]. An intense rising-edge shoulder was observed by Pappas et al. [126] in the $8985-8990 \mathrm{eV}$ range, assigned to $1 s \rightarrow 4 p$ transitions in tri-/tetra-coordinated $\mathrm{Cu}^{\mathrm{II}}$ sites (Fig. 6(b)). And the weak pre-edge peak, corresponded to the dipole-forbidden $1 s \rightarrow 3 d$ transition in $d^{9} \mathrm{Cu}^{\mathrm{II}}$ ions, was also well confirmed. In addition, the fingerprint peak of $\mathrm{Cu}^{\mathrm{II}}$ at around $8977.5 \mathrm{eV}$ slightly grew in intensity with elevated temperature, which was also consistent with a less symmetric copper coordination geometry [127]. Similarly, a feature at $8983 \mathrm{eV}$ in the XANES spectra was found during the autoreduction of $\mathrm{Cu}$-zeolite upon thermal treatment in He or under vacuum, assigned to the $1 s \rightarrow 4 p$ transition in as-formed $\mathrm{Cu}^{+}$ions [123]. The most evident variation of $\mathrm{Fe}$ is the red-shift of the edge position, which moves from $7123.6 \mathrm{eV}$ for the sample to 7122.4 and $7120.6 \mathrm{eV}$ for the samples activated at 773 and $973 \mathrm{~K}$, respectively. An even larger shift was observed by Berlier et al. [128] when the activation was isothermal at $1073 \mathrm{~K}$. These data provide clear evidence that $\mathrm{Fe}$ in the as-prepared sample is present as $\mathrm{Fe}^{3+}$, which undergo reduction to $\mathrm{Fe}^{2+}$ upon thermal activation.

As discussed above, XAS is the most direct and useful technique to determine the coordination states of TMIs in zeolite matrix even though it has some limitations. Discreet experimental arrangements (sample preparation and pretreatment) and objective data analyses (data fitting and simulation) are required to avoid any possible misleading.

\section{Catalysis by coordinatively unsaturated sites in zeolite matrix}

The aim of constructing and characterizing coordinatively unsaturated sites in zeolite matrix, ultimately, is to apply them in catalysis. In fact, coordinatively unsaturated sites in zeolite matrix have been successfully applied as irreplaceable catalysts in a series of important reactions. In this section, we will briefly discuss some representative catalytic applications classified as (1) destruction of nitrogen oxides, (2) C-H bond activation, (3) olefin conversion, (4) ring opening of epoxides and (5) activation of carbonyl groups.

\subsection{Catalytic destruction of nitrogen oxides}

Nitrogen oxides $\left(\mathrm{NO}_{x}\right.$, referring to $\mathrm{NO}$ and $\left.\mathrm{NO}_{2}\right)$, emitted from the industrial combustions and vehicle exhaust, are major air pollutants that cause a large number of environmental issues such as the acid rain, the photochemical smog, the haze and so on. To meet the stringent emission standards stipulated for environment protection, several approaches, including the commonly used three-way catalysis, the $\mathrm{NO}_{x}$ storage and reduction (NSR) and the selective catalytic reduction (SCR) of $\mathrm{NO}_{x}$, have been developed to convert the $\mathrm{NO}_{x}$ emissions to harmless nitrogen [129]. Among all these approaches, the SCR of $\mathrm{NO}_{x}$ is considered to be the most efficient technology for reducing $\mathrm{NO}_{x}$ emission from industrial sources and it has been commercialized for decades.

\subsection{1. $\mathrm{NH}_{3}-\mathrm{SCR}$}

A "Standard" $\mathrm{NH}_{3}$-SCR reaction of $\mathrm{NO}_{x}$ (mainly composed of NO) is stoichiometrically shown below:

$$
4 \mathrm{NO}+4 \mathrm{NH}_{3}+\mathrm{O}_{2}=4 \mathrm{~N}_{2}+6 \mathrm{H}_{2} \mathrm{O}
$$

And the so-called "fast" SCR reaction, occurring with equal moles of $\mathrm{NO}$ and $\mathrm{NO}_{2}$ participation, is described by the following equation:

$$
\mathrm{NO}+\mathrm{NO}_{2}+2 \mathrm{NH}_{3}=2 \mathrm{~N}_{2}+3 \mathrm{H}_{2} \mathrm{O}
$$

Generally, what actually happens during $\mathrm{NH}_{3}-\mathrm{SCR}$ is the mixture of these two reactions, and their ratio highly depends on the types of catalysts and $\mathrm{NO}_{x}$ compositions. On the basis of the researches and understanding of the catalytic activity of metal-containing zeolites in the direct decomposition of $\mathrm{NO}_{\mathrm{x}}$, various zeolite catalysts are introduced to the $\mathrm{NH}_{3}-\mathrm{SCR}$ reaction. Cu-zeolites and Fe-zeolites catalysts have been widely investigated due to their high activity and good thermal stability with respect to commercial vanadium-based catalysts [130].

Since Iwamoto et al. [131] discovered the Cu-ZSM-5 catalyst as an efficient catalyst for $\mathrm{NO}_{x}$ reduction in 1986, Cu-exchanged zeolites such as ZSM-5, beta, SSZ-13 and Y, have been widely investigated. However, their applications in the treatment of exhaust gas from diesel engine are significantly restricted due to the poor hydrothermal stability of $\mathrm{Cu}$-zeolites. On the other hand, Cu-SSZ-13 has been recently implemented as the currently standard catalyst in the mobile SCR technology due to its superior thermal durability, $\mathrm{N}_{2}$ selectivity and activity compared to other already known catalysts as well as its non-toxic properties. In 2010, Peden et al. [132] reported the detailed 
performance of $\mathrm{Cu}-\mathrm{SSZ}-13$ in $\mathrm{NH}_{3}$-SCR reaction, with comparison to Cu-beta and Cu-ZSM-5 zeolites. Surprisingly, Cu-SSZ-13 maintained its high SCR performance even after hydrothermal aging at $1073 \mathrm{~K}$.

It is generally agreed that the $\mathrm{NH}_{3}$-SCR reaction occurs on the surface of Cu-zeolites via two possible mechanisms [97]: (1) Eley-Rideal mechanism, $\mathrm{NH}_{3}$ firstly adsorbs on the Brønsted or Lewis acid sites, namely the coordinatively unsaturated $\mathrm{Cu}$ centers, then the adsorbed $\mathrm{NH}_{3}$ species react with gaseous or weakly adsorbed $\mathrm{NO}_{x}$ to produce $\mathrm{N}_{2}$ and water molecules. Lezcano-Gonzalez et al. [133] proposed that $\mathrm{NH}_{3}$ coordinated to the $\mathrm{Cu}^{2+}$ unsaturated sites was irreplaceable for the $\mathrm{NH}_{3}$-SCR reaction over the $\mathrm{Cu}-\mathrm{SSZ}-13$ catalyst, while Brønsted centers primarily acted as temporary $\mathrm{NH}_{3}$ storage sites; (2) Langmuir-Hinshelwood mechanism, the adsorbed $\mathrm{NH}_{3}$ species react with pre-chemisorbed $\mathrm{NO}_{x}$ species to fulfill the whole SCR reaction. The SCR reaction mainly happens via the reaction between adsorbed $\mathrm{NH}_{3}$ and the directly formed $\mathrm{NO}_{2}{ }^{-}$on zeolite as the first step. These adsorbed species react to form ammonia nitrites $\left(\mathrm{NH}_{4} \mathrm{NO}_{2}\right)$, which will further decompose into $\mathrm{N}_{2}$ and $\mathrm{H}_{2} \mathrm{O}$. The nitrate $\left(\mathrm{NO}_{3}-\right)$ is difficult to form due to the high reactivity of $\mathrm{NO}_{2}{ }^{-}$species, which are preferentially consumed by the adsorbed $\mathrm{NH}_{3}$ before it could be further oxidized to $\mathrm{NO}_{3}{ }^{-}$[134] .

The active centers in $\mathrm{Cu}$-SSZ-13 for $\mathrm{NH}_{3}$-SCR remain a matter of debate, probably due to the complex $\mathrm{Cu}$ species presented in the sample. Most recently researches indicate that isolated $\mathrm{Cu}$ ions in zeolites act as active centers and the SCR reaction follows a redox mechanism. That is, $\mathrm{Cu}$ ions cycle between $\mathrm{Cu}^{\mathrm{I}}$ and $\mathrm{Cu}^{\mathrm{II}}$ oxidation states during SCR reaction, which is undoubtedly a coordination catalysis process. Through the combination of kinetics analyses and theoretical calculations, the reduction half-cycle $\left(\mathrm{Cu}^{\mathrm{II}} \rightarrow \mathrm{Cu}\right)$ and the oxidation half-cycle $\left(\mathrm{Cu}^{\mathrm{I}} \rightarrow \mathrm{Cu}^{\mathrm{II}}\right)$ with periodic changing in the coordination states of Cu were established by Gao et al. [135], as shown in Fig. 7. Typically, $\left[\mathrm{Cu}^{\mathrm{II}}(\mathrm{OH})\right]^{+}$from the splitting of dinuclear copper species was regarded as the initial active site in this mechanism. NO absorbed on the $\left[\mathrm{Cu}^{\mathrm{II}}(\mathrm{OH})\right]^{+}$that were coordinated with two $\mathrm{NH}_{3}$ molecules and reacted with hydroxyl to form a HONO intermediate. This intermediate further involved in the formation of $\mathrm{NH}_{4} \mathrm{NO}_{2}$, which would finally transform to $\mathrm{N}_{2}$ and $\mathrm{H}_{2} \mathrm{O}$. Meanwhile, a $\left[\mathrm{Cu}^{\mathrm{I}}\left(\mathrm{NH}_{3}\right)\right]^{+}$was formed and underwent multiply-step interaction with $\mathrm{NH}_{3}, \mathrm{O}_{2}$ and $\mathrm{H}_{2} \mathrm{O}$ to become a new $\left[\mathrm{Cu}^{\mathrm{II}}(\mathrm{OH})\left(\mathrm{NH}_{3}\right)_{2}\right]^{+}$site to complete the cycle.

Fe-zeolites can also catalyze the $\mathrm{NH}_{3}$-SCR reaction, but the preparation of Fe-zeolites is somewhat more complicated than that of $\mathrm{Cu}$-zeolites originated from the complex solution behaviors of Fe salts. By analogy with Cu-zeolites, several possible $\mathrm{Fe}$ active sites have been postulated, i.e. tiny oxide clusters of $\mathrm{Fe}$, binuclear $\mathrm{Fe}$ species bridged by oxygen like $[\mathrm{HO}-\mathrm{Fe}-\mathrm{O}-\mathrm{Fe}-\mathrm{OH}]^{2+}$, isolated $\mathrm{Fe}^{2+}$ or $\mathrm{Fe}^{3+}$ ions, and extra-framework Fe-O-Al/Si species [136]. Gao et al. [29] concluded that the oxidation of $\mathrm{NO}$ and $\mathrm{NH}_{3}$ was catalyzed by dimeric Fe species and Fe sites with higher nuclearity, respectively. As a result, isolated $\mathrm{Fe}^{3+}$ ions acted as the preferred active sites for standard $\mathrm{NH}_{3}-\mathrm{SCR}$ at $<533 \mathrm{~K}$, while the dimeric sites catalyzed the fast $\mathrm{NH}_{3}-\mathrm{SCR}$ and parasitic $\mathrm{NH}_{3}$ oxidation. It was also proposed by $\mathrm{Li}$ et al. that the acid sites were only re-

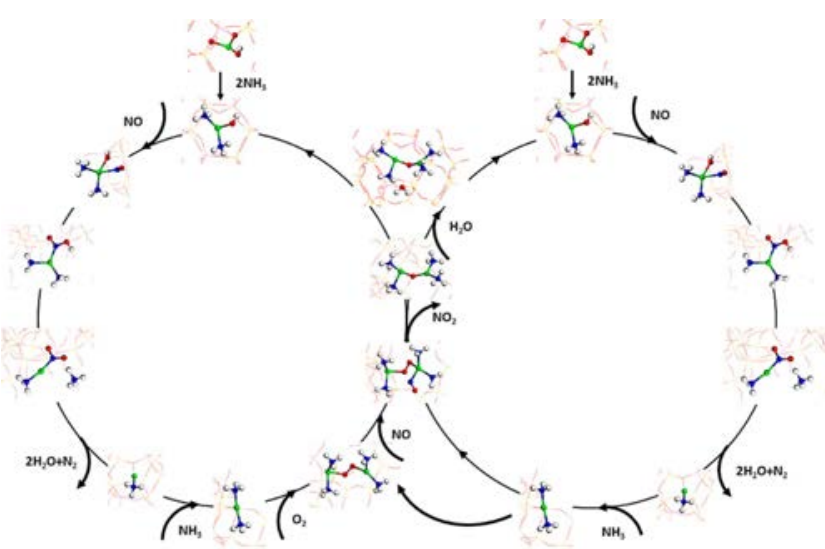

Fig. 7. The complete redox cycle of $\mathrm{NH}_{3}$-SCR according to theoretical calculations, reproduced from Ref. [135] with permission.

quired for ammonia reservation while the catalytic performance was highly related to the Fe sites with suitable redox properties. The activity trend of $\mathrm{Fe}-\mathrm{ZSM}-5$ on $\mathrm{NH}_{3}$-SCR correlated well with the EPR signal at $g^{\prime}=2.0$, indicating that the highly symmetric isolated Fe ions and/or oligomeric clusters with weak dipolar coupling acted as the feasible active sites [62]. More recently, two possible parallel mechanisms of $\mathrm{NH}_{3}$-SCR on Fe-beta were proposed by Dzwigaj et al. [137]: (1) similar Eley-Rideal mechanism to that proposed for $\mathrm{Cu}-z e o l i t e s$, i.e. reaction between chemisorbed ammonia molecules and NO from gas phase; (2) reaction of surface nitrates, from NO oxidation, with chemisorbed ammonia, the so-called Langmuir-Hinshelwood mechanism.

\subsection{2. $\mathrm{CH}_{4}-\mathrm{SCR}$}

The selective catalytic reduction of $\mathrm{NO}_{x}$ with $\mathrm{N}$-free reductants under oxygen-rich conditions appears to be more difficult than $\mathrm{NH}_{3}$-SCR [138]. However, the corrosion of ammonia and the high cost of ammonia reservation stimulate the search for alternative reductants for SCR reaction. Given the plentiful reserve of $\mathrm{CH}_{4}$ in the world, mainly from natural gas, the use of $\mathrm{CH}_{4}$ as a selective reductant should be a rational choice. In fact, the selective catalytic reduction of $\mathrm{NO}_{x}$ by methane, i.e. $\mathrm{CH}_{4}$-SCR, is an attractive technology for the post-treatment of $\mathrm{NO}_{x}$ eliminations from both stationary and mobile sources, especially when fueled by natural gas.

$$
2 \mathrm{NO}+\mathrm{O}_{2}+\mathrm{CH}_{4} \rightarrow \mathrm{N}_{2}+\mathrm{CO}_{2}+2 \mathrm{H}_{2} \mathrm{O}
$$

In very early studies, $\mathrm{Li}$ et al. $[139,140]$ investigated the $\mathrm{CH}_{4}$-SCR reaction and exploited a large amount of catalysts that were active for NO reduction in the presence of excess oxygen. Among all catalysts investigated, Co-ZSM-5 appeared to be most active for the reaction, while $\mathrm{NH}_{3}$-SCR catalyst $\mathrm{Cu}-\mathrm{ZSM}-5$ was completely inactive because the reductant methane preferred to undergo direct oxidation by excess oxygen. Besides, adding cobalt by impregnation onto conventional oxide supports like aluminium oxide only produced ineffective catalysts, revealing the essential role of zeolite matrix in hosting active cobalt species for $\mathrm{CH}_{4}$-SCR reaction. In a later work, Wichterlová et al. [24] proposed that both the protons and cobalt oxide-like species might contribute to the $\mathrm{CH}_{4}$-SCR reaction by 
promoting $\mathrm{NO}$ oxidation to $\mathrm{NO}_{2}$. The higher activity of Co-ferrierite $(\mathrm{Si} / \mathrm{Al}=8.4)$ compared with Co-ZSM-5 $(\mathrm{Si} / \mathrm{Al}=$ 12.5) was simply resulted from its higher cobalt loading (more ion-exchange sites), and the reaction rates per cobalt atom of the two catalyst were comparable. A similar conclusion was drawn by Indovina et al. according to the linear correlation between the catalytic activity in $\mathrm{CH}_{4}$-SCR and the concentration of $\mathrm{Co}^{2+}$ ions with both Co-ZSM-5 [141] and Co-mordenite [142].

For the rational design of eligible catalysts for $\mathrm{CH}_{4}-\mathrm{SCR}$, understanding of the reaction mechanism is undoubtedly necessary. The mechanism of the $\mathrm{CH}_{4}$-SCR is distinctly different from that of the $\mathrm{NH}_{3}-\mathrm{SCR}$, and both the activation of methane and the formation of N-N bond should occur to trigger the reaction. The most obvious difference is that in $\mathrm{CH}_{4}$-SCR, NO molecules preferentially absorb and transform to surface intermediate such as $\mathrm{N}_{x} \mathrm{O}_{y}$ species, which then react with gaseous methane. While in $\mathrm{NH}_{3}$-SCR, ammonia molecules absorb first and then react with chemisorbed $\mathrm{N}_{x} \mathrm{O}_{y}$ species or gaseous NO. A typical $\mathrm{CH}_{4}-\mathrm{SCR}$ mechanism catalyzed by Co-zeolites was established by Li et al. [140], where the changes in the coordination states of cobalt centers could be clearly seen:

$$
\begin{gathered}
\mathrm{Z}-\mathrm{Co}+\mathrm{NO} \rightarrow \mathrm{Z}-\mathrm{CO}-\mathrm{NO} \\
\mathrm{Z}-\mathrm{Co}-\mathrm{NO}+\frac{1}{2} \mathrm{O}_{2} \rightarrow \mathrm{Z}-\mathrm{Co}-\mathrm{NO}_{2} \\
\mathrm{CH}_{4}+\mathrm{Z}-\mathrm{Co}-\mathrm{NO}_{2} \rightarrow \mathrm{CH}_{3}+\mathrm{Z}-\mathrm{CO}-\mathrm{HNO}_{2} \\
\mathrm{CH}_{3}+\mathrm{Z}-\mathrm{Co}-\mathrm{NO}_{2} \rightarrow \mathrm{Z}-\mathrm{CO}-\mathrm{NO}_{2} \mathrm{CH}_{3} \\
\mathrm{Z}-\mathrm{Co}-\mathrm{NO}_{2} \mathrm{CH}+\mathrm{NO} \rightarrow \mathrm{N}_{2}+\mathrm{CO}+\mathrm{H}_{2} \mathrm{O}+\mathrm{Z}-\mathrm{CO}-\mathrm{OH} \\
\mathrm{Z}-\mathrm{Co}-\mathrm{OH}+\mathrm{NO} \rightarrow \mathrm{Z}-\mathrm{CO}-\mathrm{HNO} 2 \\
2 \mathrm{Z}-\mathrm{Co}-\mathrm{HNO}_{2} \rightarrow \mathrm{NO}+\mathrm{NO}_{2}+\mathrm{H}_{2} \mathrm{O}+2 \mathrm{Z}-\mathrm{CO} \\
\mathrm{CO}+\frac{1}{2} \mathrm{O}_{2} \rightarrow \mathrm{CO}_{2}(\mathrm{Z}=\mathrm{Zeolite})
\end{gathered}
$$

Among all these steps, the formation of adsorbed $\mathrm{NO}_{2}$ or $\mathrm{N}_{x} \mathrm{O}_{y}$ species on $\mathrm{Co}^{2+}$ sites is a necessary step. NO is thought to be oxidized through Mars-van Krevelen mechanism by gaseous oxygen. The cobalt sites of catalyst split oxygen molecules into atoms and then act as a kind of reservoir that can take up these atoms and release them to form surface intermediate. That is, the catalyst can be both a 'divorce lawyer' and a 'marriage broker'. The isolated $\mathrm{Co}^{2+}$ cations facilitate the chemisorption of NO and act as storage sites for NO, taking advantages of their characters of coordinative unsaturation. Considering the fact that methane is consumed mainly for $\mathrm{NO}_{x}$ reduction instead of direct combustion, $\mathrm{NO}_{x}$ molecules play a key role in activating $\mathrm{CH}_{4}$ or $\mathrm{C}-\mathrm{H}$ bond cleavage is facilitated by surface $\mathrm{NO}_{2}$ species. The rate-determining step (RDS) may be the breaking of the $\mathrm{C}-\mathrm{H}$ bond or the oxidation of NO on cobalt sites. An unavoidable side reaction is $\mathrm{CH}_{4}$ combustion which can also proceed on isolated $\mathrm{Co}^{2+}$ sites. Fortunately, this does not alter the RDS but decreases the effective concentration of methane for $\mathrm{CH}_{4}$-SCR reaction and therefore leads to lower deNO$_{\mathrm{x}}$ activity [143].

\subsection{Catalytic activation of $\mathrm{C}-\mathrm{H}$ bond}

In the mechanism study of $\mathrm{CH}_{4}-\mathrm{SCR}$, the activation of $\mathrm{C}-\mathrm{H}$ bond in methane is involved. In fact, the activation and functionalization of $\mathrm{C}-\mathrm{H}$ in alkanes or cycloalkanes are always hot research topic in organic synthetic chemistry, which are closely related to our daily life. For example, the selective oxidation of cyclohexane to cyclohexanol and cyclohexanone, i.e. KA oil, is a key step in the commercial production of nylon. Thomas et al. [144-146] had explored framework-substituted Co/Mn/Fe aluminum phosphates (AlPOs) as catalysts for the aerobic selective oxidation of cyclohexane to KA oil. Furthermore, they extended this type of reaction to oxidation of linear alkanes, which can produce adipic acid, an upstream raw material of nylon and other synthetic materials. Since the $\mathrm{C}-\mathrm{H}$ bond activation is such a big topic, we can only briefly discuss the catalytic functionalities of coordinatively unsaturated sites in zeolites in serval important reactions, i.e. methane hydroxylation, benzene hydroxylation and oxidative dehydrogenation of propane.

\subsubsection{Methane hydroxylation}

As one form of traditional fossil energy, methane offers a rich source of hydrogen atoms, if its $\mathrm{C}-\mathrm{H}$ bond could be effectively activated. The catalytic and/or autothermal reforming of methane at very high temperatures has been commercialized for the production hydrogen. Nowadays, much of the research interest in methane activation is focused on the conversion of methane to value added oxygenates such as methanol and acetic acid under relatively mild conditions. Such reactions are very challenging due to the extremely high $\mathrm{C}-\mathrm{H}$ bond energy of $104 \mathrm{kcal} / \mathrm{mol}$ in methane and the fact that the desired products are much more reactive than methane [147]. In this context, methane hydroxylation to produce methanol has been re-focused recently with the using of coordinatively unsaturated $\mathrm{Cu}$ or $\mathrm{Fe}$ cationic centers in zeolites as catalysts.

The ability of Cu-zeolites to selectively catalyze methane to methanol was disclosed by Schoonheydt et al. [148]. Methanol could be formed in high selectivity on $\mathrm{Cu}-\mathrm{ZSM}-5$ with methane after being activated in $\mathrm{O}_{2}$ atmosphere and the strongly adsorbed methanol product on the zeolite could be extracted by solvent, e.g. water. Since then, researches on the catalytic methane hydroxylation with $\mathrm{Cu}$-zeolites flourish. The wisdom of nature is widely imitated by human beings like inventing airplane at the sight of flying birds. A particulate methane monooxygenase (pMMO) found in methanotropic bacteria is known to catalyze such methane hydroxylation reaction at ambient conditions. Mononuclear and dinuclear $\mathrm{Cu}$ sites, the latter being identified as the active site with cyclic oxidation states of $\mathrm{Cu}^{\mathrm{I}}$ and $\mathrm{Cu}^{\mathrm{II}}$, are confirmed to exist in one of the subunit of pMMO [149]. Inspired by nature, new catalysts, e.g. Cu-mordenite, Cu-SSZ-13, Cu-SSZ-39, Cu-ZSM-5, Cu-SAPO-34, could be rationally designed by constructing similar sites in zeolite matrix. Meanwhile, different active $\mathrm{Cu}$ sites, e.g. mono( $\mu$-oxo) dicopper site and trinuclear copper oxygen clusters, have been proposed for methane hydroxylation. The existence and activity of trinuclear copper oxygen clusters in $\mathrm{Cu}$-mordenite zeolite prepared by ion exchange was recently proposed and confirmed by Lercher et al. [150].

It should be emphasized that the mono( $\mu$-oxo) dicopper species, resembled to dinuclear $\mathrm{Cu}$ sites in nature pMMO, is more widely accepted as the active sites for methane hydroxylation, which is also verified by the combination of spectroscopic characterizations and theoretical calculations. The 
unique configuration of mono( $\mu$-oxo) dicopper species enables oxygen, nitrous oxide and even inert water to act as the oxidants to abstract $\mathrm{H}$ atom from $\mathrm{CH}_{4}$. These species show characteristic charge transfer (CT) band at around $22700 \mathrm{~cm}^{-1}$ in operando UV-vis-NIR DRS measurement, which disappear after dosing of methane [148]. In a typical methane activation process, a $\mathrm{CH}_{3}$ fragment forms and coordinates to the copper center of the active site after $\mathrm{C}-\mathrm{H}$ bond cracking (proton abstracted by the zeolite framework), which is responsible for disappearance of the characteristic band in UV-vis-NIR spectrum. Oxidants like oxygen subsequently take part in the reaction and accelerate the generation and desorption of methanol product with the regeneration of copper active sites. The valence state and the coordination number of copper show periodic changes in the whole process, which can be monitored by in situ XPS, XANES and supplemented by theoretical calculations. $\mathrm{CD}_{4}$ and $\mathrm{CH}_{2} \mathrm{D}_{2}$ can be employed as reactants instead of methane, which bring about a large H/D kinetic isotope effect of $\sim 3$ [16]. These observations indicate that $\mathrm{C}-\mathrm{H}$ cleavage is involved in the RDS of methane hydroxylation. The actual reaction process of methane hydroxylation on Cu-zeolite is still to be confirmed by more direct spectroscopic evidence and herein we just try to elaborate this problem with focus on the important role of coordinatively unsaturated $\mathrm{Cu}$ sites.

In case of using water as oxidant proposed in recent work, the formation of hydrogen was clearly observed before the appearance of methanol signals in mass spectrum. The oxygen atom of water played a key role in re-oxidize the $\mathrm{Cu}$ sites that were reduced by interaction with methane. Meanwhile, the hydrogen atoms assembled to form molecular hydrogen, which could easily desorb from the zeolite [151].

Since there is a paralleled soluble methane monooxygenase containing active Fe sites, the Fe-zeolites, e.g. Fe-ZSM-5, Fe-SSZ-13 and Fe-beta, are also prepared and applied in methane hydroxylation. Special catalytic active $\mathrm{Fe}$ sites, i.e. so-called $\alpha$-sites, can be formed at $773 \mathrm{~K}$ with the $\mathrm{Fe}^{3+} \rightarrow \mathrm{Fe}^{2+}$ reduction. These $\alpha$-Fe sites can transform to mononuclear $\mathrm{S}=2$ $\mathrm{Fe}(\mathrm{IV})=0$ reactive intermediates or $\alpha-0$ sites upon interaction with nitrous oxide $[33,38,152]$. Solomon and co-workers have evidenced that the active sites in $\mathrm{Cu}$-zeolites and Fe-zeolites are analogous to those in metalloenzymes $[17,153]$, and more detailed information can be found in the recent review article [154].

\subsubsection{Benzene hydroxylation}

Other $\mathrm{C}-\mathrm{H}$ bonds can also be activated by $\alpha-\mathrm{O}$ species on Fe-zeolites and the unique behaviors of $\alpha-0$ species are investigated by theoretical calculations [155]. Similar to methane hydroxylation, the hydroxylation of benzene to phenol can be achieved with Fe-zeolites as catalysts and nitrous oxide as an oxidant. This process shows obvious advantages as compared with the conventional three-step peroxidation of cumene, avoiding the generation of large amounts of byproduct and waste. Sachtler et al. [156] investigated Fe-ZSM-5 catalysts and found that mononuclear Fe sites could catalyze benzene oxidation to phenol while dinuclear sites facilitated nitrous oxide reduction to nitrogen. The side reaction of benzene combustion was catalyzed by the undesired Fe-oxide nanoparticles. Catalytic deactivation was also observed for this reaction due to the poisoning of active Fe sites by the presence of $\mathrm{H}_{2} \mathrm{~S}$ with higher coordination ability toward Fe sites. It was proposed by Lamberti et al. [157] that the coordinatively unsaturated Fe sites in zeolite framework could also catalyze benzene hydroxylation. The catalytic activity could be tuned by tuning the degree of $\mathrm{Fe}$ coordination through simple steaming treatment and activation at different temperatures. More recently, Hensen et al. [61] synthesized Fe-ZSM-5 nanosheets using the strategy of encapsulation and shone lights on the rational optimization of benzene hydroxylation reaction conditions.

\subsubsection{Oxidative dehydrogenation of propane}

The talented catalytic behaviors of Fe-zeolites with nitrous oxide are also applied in another type of $\mathrm{C}-\mathrm{H}$ bond activation reaction, i.e. the oxidative dehydrogenation of light alkanes to alkenes (for example the oxidative dehydrogenation of propane to propylene, ODHP). Light olefins are very important components for the petrochemical industry with increasing demands. The oxidative dehydrogenation of light alkanes offers an alternative route to the traditional catalytic cracking or the newly established methanol-to-olefins conversion for alkenes production. Compared with ODHP with oxygen, the use of nitrous oxide an oxidant (that can be called $\mathrm{N}_{2} \mathrm{O}$-mediated ODHP) brings significant advantages in high propylene selectivity and slow deactivation rate, but the catalysts are limited to Fe-zeolites and analogues.

Pérez-Ramírez et al. [158-162] have made great efforts on $\mathrm{N}_{2} \mathrm{O}$-mediated ODHP with Fe-zeolite catalysts. The extraction of framework Fe species to extraframework Fe species through steam treatment was found to be essential to produce active catalysts for $\mathrm{N}_{2} \mathrm{O}$-mediated ODHP [158]. The zeolite host and acidity of Fe-zeolites did not show significant impacts on the initial propene yield, but strongly influenced the deactivation behavior. Oligonuclear $\mathrm{Fe}_{x} \mathrm{O}_{y}$ clusters were proposed to be more active than isolated Fe species for this reaction [159]. During ODHP reaction, monooxygen species were created on Fe-zeolite upon interaction with nitrous oxide, which could not be realized with dioxygen instead of nitrous oxide.

In contrast, it was proposed by Li et al. $[163,164]$ that the framework structures indeed showed significant impacts on the catalytic behaviors of Fe-zeolites in $\mathrm{N}_{2} \mathrm{O}$-mediated ODHP reaction and the sample calcination temperatures were equally important. It is easy to understand since both the framework structures and the calcination post-treatments can modulate the constitution of $\mathrm{Fe}$ sites in Fe-zeolites. Extra-framework $\mathrm{Fe}-\mathrm{O}-\mathrm{Al}$ species were confirmed to be preferred active species according to the correlation between content of exposed active iron sites and the corresponding catalytic activities. The well-known $\alpha-\mathrm{O}$ on the $\mathrm{Fe}-\mathrm{O}-\mathrm{Al}$ species were assigned to be key oxygen species for ODHP, and their reaction with gaseous propane via Eley-Rideal mechanism was the key step of propylene production. The simplified reaction pathway is represented as follows:

$$
\begin{aligned}
\mathrm{Fe}^{2+}+\mathrm{N}_{2} \mathrm{O} & \rightarrow \mathrm{N}_{2}+\mathrm{Fe}^{2+}-\mathrm{O} \\
\mathrm{Fe}^{2+}-\mathrm{O} & \rightarrow \mathrm{Fe}^{3+}-\mathrm{O}^{-}
\end{aligned}
$$




$$
\mathrm{Fe}^{3+}-\mathrm{O}^{-}+\mathrm{C}_{3} \mathrm{H}_{8} \rightarrow \mathrm{Fe}^{2+}+\mathrm{C}_{3} \mathrm{H}_{6}+\mathrm{H}_{2} \mathrm{O}
$$

Catalytic deactivation is a very important issue in $\mathrm{N}_{2} \mathrm{O}$-mediated ODHP, which is usually explained by the gradual formation and deposition of coke on the surface of catalyst. Pérez-Ramírez et al. [161,162] found that propylene was the main precursor of coke based on a linear relation between the yield of propylene and the coke content. Fortunately, the deactivated catalyst could be fully recovered through the calcination removal of coke. In this context, a mature $\mathrm{N}_{2} \mathrm{O}$-mediated ODHP process should be a cyclic reaction including the regeneration of catalyst.

In addition to Fe-zeolites, other TMIs-zeolites such as Co-zeolites and $\mathrm{Cr}$-zeolites have been applied in $\mathrm{N}_{2} \mathrm{O}$-mediated ODHP reaction while their catalytic activity appears to be somewhat lower than Fe-zeolites [165-168].

\subsection{Catalytic functionalizationfunctionalization of olefins}

The olefins with unsaturated $\mathrm{C}=\mathrm{C}$ bonds can undergo polymerization to molecules with higher formula weights or transform to the corresponding saturated products with the addition of hydrogen, hydrogen halides and water. On the other hand, olefins can also react with molecular oxygen or hydrogen peroxide or alkyl peroxide like $t$-butyl-hydroperoxide (TBHP) to produce the epoxides, which are very important raw materials in chemical industry. Many TMI-containing zeolites, e.g. Ti-zeolites and Co-zeolites, have been reported to be active for the epoxidation of olefins. In this section, we will emphasis on the ethylene oligomerization and olefin epoxidation catalyzed by coordinatively unsaturated sites in zeolite matrix.

\subsubsection{Ethylene oligomerization}

Currently, ethylene is dominantly produced from crude oil derivatives via steam cracking, while various alternative routes involving natural gas, coal, and biomass as starting materials have proven their industrial potential [169]. Linear $\alpha$-olefins (LAOs) are important precursors or intermediates for the synthesis of a wide range of industrial products such as detergents, synthetic lubricants, surfactants and amines. Short-chain LAOs $\left(\mathrm{C}_{4}-\mathrm{C}_{6}\right)$ are also used as co-monomers in the production of linear low-density polyethylene. On the industrial scale, LAOs are produced through the liquid-phase oligomerization of ethylene using homogeneous catalysts comprising a transition metal (e.g. Ti, Ni, Co, Cr and Fe) complex, assisted by an alkyl aluminum (e.g. methylaluminoxane) or hydride co-catalyst, namely, Ziegler-Natta catalyst [170]. The function of co-catalyst in the homogeneous systems is to alkylate the metal center, providing the first metal-carbon bond on which the oligomerization can then proceed through the classical Cossee-Arlman pathway. The homogeneous phase oligomerization processes suffer from several drawbacks, such as the high sensitivity of the organometallic catalyst to impurities in the feed and the costly separation of the catalyst from the products.

Heterogeneous catalysis is an eco-friendly alternative to the Ziegler-Natta catalyst concerning the principles of green chemistry. Among all heterogeneous catalysts investigated, $\mathrm{Ni}$-zeolites present a comparable performance toward ethylene oligomerization. Typically, Ni-X and Ni-Y catalysts were employed in the ethylene dimerization and oligomerization $[171,172]$ and later on, Ni-SAPO-5, Ni-SAPO-11 and Ni-beta were synthesized and applied in the reaction [173,174]. Extensive researches have been performed on ethylene dimerization over Ni-zeolites in order to reveal the nature of the active sites as well as the reaction kinetics [171,175]. Dimerization is the elementary step of oligomerization, and long-chain olefins can be produced under more severe conditions, i.e. higher temperature and pressure.

The catalytic properties of Ni-zeolites in ethylene oligomerization strongly depend on the nature of the $\mathrm{Ni}$ active sites. Martinez et al. regarded $\mathrm{Ni}^{2+}$ cations in exchange positions in the Ni-beta zeolite as active sites of oligomerization, while the probably existent $\mathrm{Ni}^{+}$species acted as spectators [174]. Bonneviot et al. [172] reported that $\mathrm{Ni}-\mathrm{X}$ exhibited high activity in ethylene and propylene oligomerization. It was interesting to note that the coordination numbers of $\mathrm{Ni}$ centers changed under different pretreat temperatures. Typically, the Ni-X catalyst was selective for dimerization when it was treated at $773 \mathrm{~K}$, when two molecules of olefins were bonded to the same $\mathrm{Ni}^{+}$ under this condition. After treatment at $973 \mathrm{~K}$, the $\mathrm{Ni}^{+}$centers in zeolites $\mathrm{X}$ were more coordinatively unsaturated and both dimerization and trimerization would occur. Overall, the real active sites for ethylene oligomerization are still under debate and delicate spectroscopy techniques should be employed to characterize Ni-zeolites in action. The classical Cossee-Arlman pathway was proposed for ethylene oligomerization on Ni-zeolites by Brogaard et al. [176] according to their theoretical calculations. Most recently, Martínez et al. [177] proposed a similar mechanism for the initial activation-dimerization of ethylene on the active $\mathrm{Ni}^{2+}$ sites, which involved a nickel ethenyl hydride intermediate generated on the $\mathrm{Ni}^{2+}$ site, as shown in Scheme 3.

Despite of extensive researches and some remarkable results reported, there is a long way to go for the industrial applications of ethylene oligomerization catalyzed by Ni-zeolites. Currently, it is most urgently to get the fundamental knowledge on the active sites and the reaction mechanism for the rational design of eligible Ni-zeolite catalysts.

\subsubsection{Epoxidation of olefins}

For the epoxidation of olefins, we will focus on two representative reactions, i.e. styrene epoxidation with molecular oxygen on Co-zeolites and lower olefins epoxidation with TBHP or hydrogen peroxide on Ti-zeolites.

Epoxyethylbenzene or styrene oxide is a crucial raw material for the manufacturing of $\beta$-phenethyl alcohol, phenylacetaldehyde, tetramisole and its levorotatory form as well as levamisole, which have shown wide applications in the petrochemical industry, fine chemistry, perfumery and pharmacy. Epoxyethylbenzene can be produced from styrene epoxidation with water as the sole byproduct and the use of dioxygen for styrene epoxidation is more desirable considering the eco-friendly, safety and economic concerns. However, as a conventional radical reaction, trace mount of TBHP is usually necessary as initiating agent of free radicals for epoxidation. 


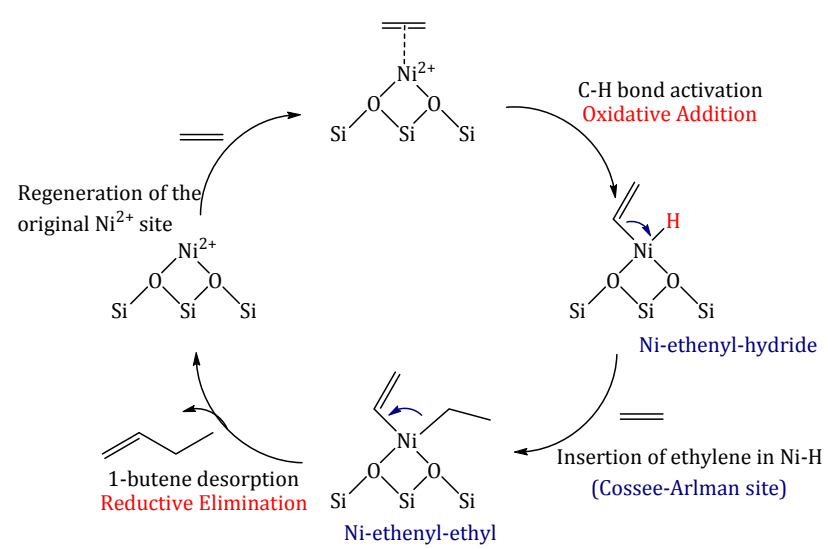

Scheme 3. The catalytic cycle for ethylene dimerization on the active $\mathrm{Ni}^{2+}$ centers in Ni-BEA catalyst, reproduced from Ref. [177] with permission.

Cobalt ions and their complexes are conventional catalysts for the aerobic oxidation of alkanes and alkylbenzenes [178]. Wang et al. [179] prepared Co-FAU zeolites via simple WIE route and applied them as catalysts in the epoxidation of styrene to epoxyethylbenzene with the presence of solvent $\mathrm{N}, \mathrm{N}$-dimethylformamide (DMF). DMF was initially selected as solvent due to its high oxygen-dissolving capacity, while it played an important role in the epoxidation reaction through constructing tetrahedral $\mathrm{Co}^{\mathrm{II}}$ active site via prior coordination. Later on, Jasra et al. [180] further investigated the detailed reaction process, and a tentative mechanism was proposed as follows (Scheme 1). Obviously, this is a typical coordination catalysis process. The empty orbits of coordinatively unsaturated cobalt centers promoted by solvent DMF behave as the storage sites for both dioxygen and $\mathrm{C}=\mathrm{C}$ bond. The desorbed cyclic peroxide radical (IV) could further react with another molecule of styrene to give two styrene epoxide molecules or decompose to benzaldehyde and formaldehyde. The presence of benzaldehyde and formaldehyde as byproducts from styrene epoxidation is then well explained.

The primary strategy of olefin epoxidation was accomplished by using transition metal complexes with organic hydroperoxides, as published by Indictor et al. [181]. Replacing the transition metal complexes by heterogeneous catalysts with high substrate conversion and product selectivity under mild conditions is undoubtedly significant to industrial applications. Epoxidation of olefins with TBHP or hydrogen peroxide $\left(\mathrm{H}_{2} \mathrm{O}_{2}\right)$ catalyzed by Ti-zeolites, e.g. Ti-MFI, Ti-BEA, Ti-MTW and Ti-MWW, has been extensively investigated shortly after the successful synthesis of these samples [44,45,182,183]. Generally, the tetra-coordinated framework $\mathrm{Ti}^{\mathrm{IV}}$, as evidenced by the characterization results from FTIR, UV-Vis DRS and XAS (see details in Section 3), act as dominating active sites in Ti-zeolites that lead to excellent reactivity in olefin epoxidation. The use of $\mathrm{H}_{2} \mathrm{O}_{2}$ instead of organic hydroperoxides as the sacrificial oxidant also shows significant advantages in terms of environmental and economic considerations since water is produced as the sole by-product in epoxidation with $\mathrm{H}_{2} \mathrm{O}_{2}$. The epoxidation of olefins catalyzed by Ti-zeolites can be operated in both liquid and gas phase (for example in the cases of ethylene and

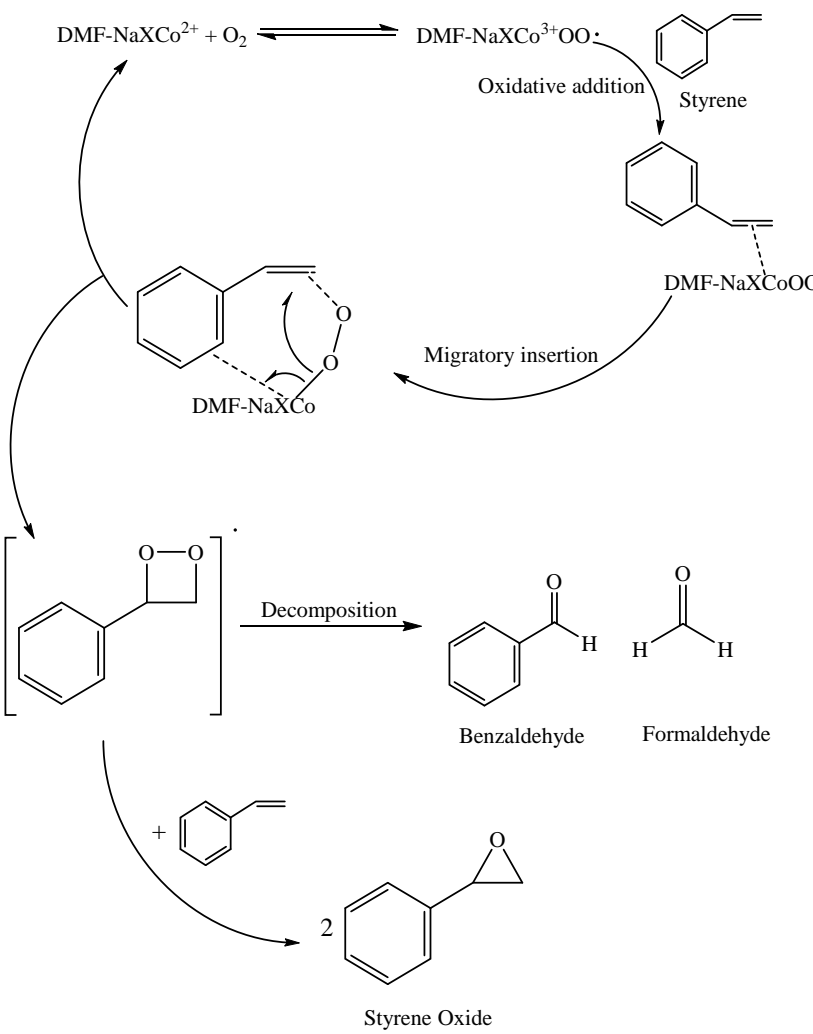

Scheme 4. The reaction mechanism for styrene epoxidation on Co-FAU catalyst, reproduced from Ref. [180] with permission.

propylene). In a very general sense, solvent with low polarity is preferred for epoxidation in the liquid phase since strong polar solvent can occupy the active Ti sites and hinder the adsorption of olefin substrates [184].

The discovery of TS-1 (Ti incorporated into the framework of Silicalite-1, MFI topology) is a milestone in zeolite history due to its remarkable catalytic performance in the epoxidation of linear alkenes, cyclic olefins and even macrocyclic terpenes [185]. Nowadays, TS-1 is still recognized as a benchmark epoxidation catalyst when evaluating the performance of a newly-prepared Ti-zeolites. Clerici et al. [186] investigated the epoxidation of lower olefins and found that the reaction rate depended not only on intrinsic properties of Ti active sites, but also on the position of the double bond and the steric configurations of reaction substrates. Yashima et al. [187] reported a Ti-MWW zeolite with much higher catalytic activity in 1-hexene epoxidation than TS-1. Typically, Ti-MWW ( $\mathrm{Si} / \mathrm{Ti}=38$ ) showed $44.8 \%$ 1-hexene conversion with 99\% selectivity toward corresponding epoxide, while the 1-hexene conversion over TS-1 under the same reaction condition was as low as 5.8\%. In addition to Ti-zeolites from direct hydrothermal synthesis, Ti-zeolites from post-synthesis modifications, with similar tetra-coordinated framework Ti centers, exhibited very promising catalytic activity in the reaction of olefin epoxidation. For example, higher epoxidation activity than TS-1 with comparable selectivity toward corresponding epoxide was achieved over Ti-beta [10], resulting from its larger pore sizes and improved diffusion of bulky substrate. Meanwhile, a quasilinear correlation between the epoxidation reaction rate and the content of 
framework tetra-coordinated $\mathrm{Ti}^{\mathrm{IV}}$ centers could be drawn, revealing that those $\mathrm{Ti}^{\mathrm{IV}}$ species in Ti-Beta acted as active centers for epoxidation reaction.

\subsection{Catalytic ring opening of epoxides}

In the researches of olefin epoxidations (with $\mathrm{H}_{2} \mathrm{O}_{2}$ as oxidant), traces of diols could be detected as by-products together with epoxides, indicating that the epoxidation catalysts might also be active in the ring opening hydration of epoxides. In fact, epoxides are very important carbon electrophilic reagents and can be further functionalized. Due to the tension of three-member hetero-ring in epoxides, the $\mathrm{C}-\mathrm{O}$ bond in the epoxy ring can be easily broken under the attack of the nucleophilic reagent, leading to the ring opening of epoxy compound. In general, common nucleophilic reagents include O-containing molecules (for example water, alcohol, phenol and acid), $\mathrm{N}$-containing molecules (for example ammonia, amine, and azide) and S-containing molecules [14]. The ring opening of epoxides with nucleophilic reagents such as amines and alcohols is currently recognized as one of the most useful reactions in the chemical industry for the production of bifunctional molecules.

\subsubsection{Hydration of epoxide}

The direct hydration of ethylene oxide (EO) is the dominating route to produce ethylene glycol (also called as mono-ethylene glycol, MEG) on industrial scale, which is commonly used as an automotive antifreeze, or as an ingredient in solvents, or as a key starting material to polyesters, explosives, alkyd resins, synthetic waxes and so on [188]. About 30 million metric tons of MEG is made annually from the liquid-phase hydration of EO. In this process, a large excess of water $\left(\mathrm{H}_{2} \mathrm{O} / \mathrm{EO}=\sim 20\right)$ is employed to ensure a high conversion of EO and, more importantly, a high selectivity toward MEG. The obtained diluted aqueous MEG solution undergoes further distillation to final product, which makes MEG production one of the most energy-intensive processes in the chemical industry.

The catalytic hydration of EO can be achieved with Lewis acid catalysts with coordinatively unsaturated sites, e.g. metal-salen complexes and Lewis acidic zeolites, even under mild reaction conditions. However, the formation of diethylene glycol (DEG) and triethylene glycol (TEG) byproducts via self-condensation of MEG, occurs at high EO conversions in most cases. To solve the problem, Li et al. [189] developed a nanoreactor by encapsulating $\mathrm{Co}^{\mathrm{III}}$ (salen) molecular catalyst in the nanocage of mesoporous silica, which could catalyze the EO hydration with EO conversion of $>98 \%$ and MEG selectivity of $>98 \%$ under the $\mathrm{H}_{2} \mathrm{O} / \mathrm{EO}$ ratio of 2 . On the other hand, Li et al. [190] developed a robust Sn-H-SSZ-13 catalyst for EO hydration with the combination of coordinatively unsaturated site for Lewis acid catalysis and the concept of shape-selective catalysis in zeolite. Typically, the Sn-SSZ-13 was prepared through a simple partial dealumination and subsequent dry impregnation with $\left(\mathrm{CH}_{3}\right)_{2} \mathrm{SnCl}_{2}$ followed by calcination. The specific pore openings of SSZ-13 (kinetic diameter: $0.42 \mathrm{~nm}$ ) allowed the free diffusion of $\mathrm{EO}$ and $\mathrm{H}_{2} \mathrm{O}$ as well as the target product MEG but hindered the diffusion of DEG and TEG byproducts, thus realizing the shape-selective hydration of EO to MEG. The strong Lewis acid sites created by framework tetrahedrally coordinated Sn species, as evidenced by UV-vis, ${ }^{119}$ Sn MAS NMR and XPS, ensured the occurrence of EO hydration reaction under mild conditions. Remarkably, EO conversion of $>99 \%$ and MEG selectivity of $>99 \%$ could be simultaneously achieved at $313 \mathrm{~K}$ with the $\mathrm{H}_{2} \mathrm{O} / \mathrm{EO}$ ratio of 2 . Besides, the Sn-H-SSZ-13 heterogeneous catalyst system showed perfect recyclability, demonstrating its great potential for industrial applications. The EO hydration over tetrahedrally coordinated Sn species in Sn-zeolite, with $\mathrm{Sn}(\mathrm{OSi})(\mathrm{OH})_{3}$ as an example, undergo typical coordination catalysis process. As shown in the Fig. 8(a), the reaction involved the EO addition into four-coordinated Sn center to generate five-coordinated $\mathrm{Sn}$ center, the $\mathrm{H}_{2} \mathrm{O}$ coordination to generate six-coordinated Sn center and subsequent proton transfer, and the final escape of MEG with the regeneration of four-coordinated Sn center. Theoretical calculations further revealed that the coordination states of Sn centers showed significant impacts on the energy barrier of EO hydration and partially hydroxylated $\mathrm{Sn}$ species in Sn-zeolite, i.e. $\mathrm{Sn}(\mathrm{OSi})(\mathrm{OH})_{3}$, acted as the preferred active sites for the reaction (Fig. 8(b)).

\subsubsection{Aminolysis and alcoholysis of epoxides}

Similar to the cases of epoxide hydration, epoxides aminolysis toward $\beta$-amino alcohols and alcoholysis toward $\beta$-alkoxy alcohols are also known as important reactions in fine chemistry and pharmacy. $\beta$-amino alcohols are widely used in the synthesis of non-natural amino acids, $\beta$-blockers, pesticides, and oxazolines while $\beta$-alkoxy alcohols are used as versatile intermediates for the synthesis of several pharmaceutical compounds such as anti-tumors and immune-suppressors [191].

Ti-zeolites was applied as catalysts in the epoxides aminolysis by Srinivas et al. [192] as early as 2007. A range of $\beta$-amino alcohols could be synthesized with Ti-zeolites at room temperature and under solvent-free conditions. The selectivity toward $\beta$-amino alcohols was higher than other traditional catalysts such as liquid acids and metal halides. Later on, Srivastava et al. [193] synthesized Ti/Zr-MFI nanocrystallines and applied them in both aminolysis and alcoholysis of epoxides. It was found that the Lewis acidity from created from the isomorphous substitution of Zr in MFI zeolite was responsible for the high catalytic activity of Zr-MFI in the reaction. Similarly, Zr-BEA from post-synthesis modifications was active in the ring opening aminolysis of epoxides and high regio-selectivity toward $\beta$-amino alcohols could be achieved [11]. The presence of mesopores in Zr-BEA could further promote its catalytic activity and suppress catalytic deactivation by enhanced mass transfer. Zr-MOR zeolites with large pores were successfully synthesized by Zhao et al. [194], and showed high activity and regio-selectivity in the ring opening aminolysis of epoxides to the $\beta$-amino alcohols under ambient and solvent-free conditions. The unique catalytic performance of Zr-zeolites in the aminolysis of was relevant with the competitive adsorption and balance between epoxide substrates and amine reactants on 
(a)

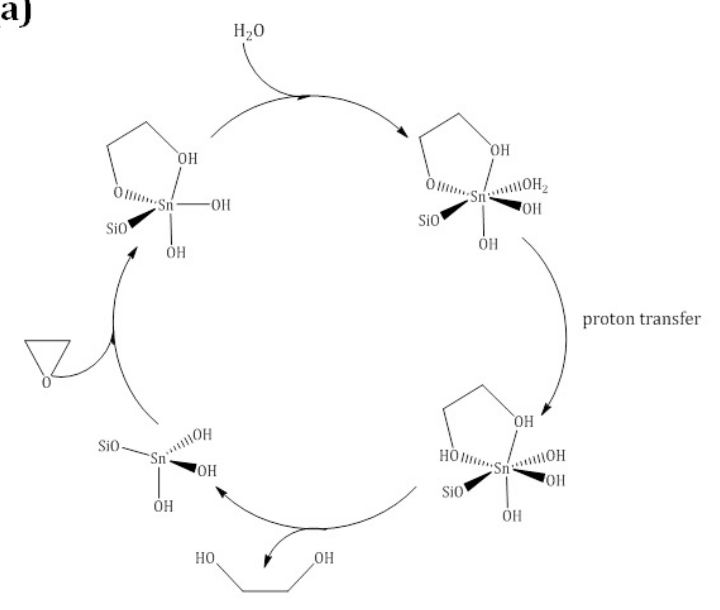

(b)

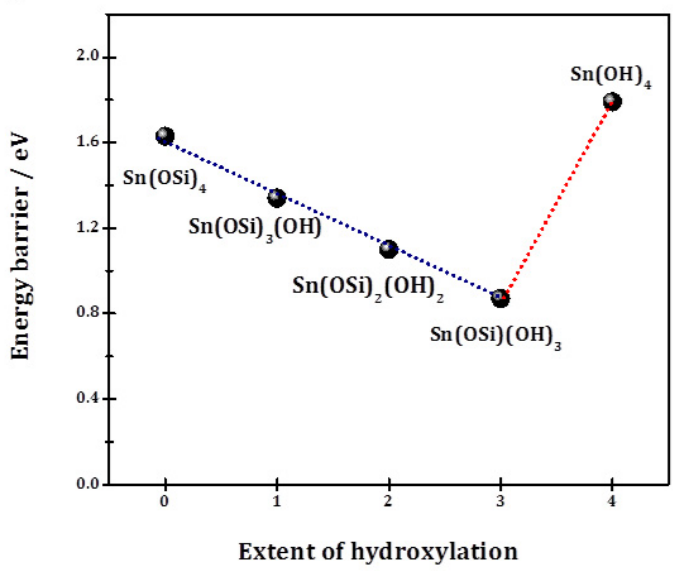

Fig. 8. (a) Reaction pathway of EO hydration catalyzed by the open $\mathrm{Sn}(\mathrm{OSi})(\mathrm{OH})_{3}$ site in Sn-H-CHA; (b) The intrinsic energy barriers for EO hydration on Sn-H-CHA with different active Sn sites, reproduced from Ref. [190] with permission.

coordinatively unsaturated $\mathrm{Zr}$ centers. However, when amines with high basicity, e.g. butylamine, were employed as reactants, Zr-zeolites exhibited quite low activity due to the strong adsorption of amines and occupation of $\mathrm{Zr}$ centers. To address this issue, Pb-BEA zeolites were synthesized via post-synthesis modifications and applied as efficient catalysts in the reaction of epichlorohydrin and butylamine [77]. On Pb-BEA, the adsorption of both epichlorohydrin and butylamine on $\mathrm{Pb}$ sites were possible, thus enabling the bimolecular reaction probably via Langmuir-Hinshelwood mechanism.

\subsection{Catalytic activation of carbonyl groups}

Lewis acids are playing more and more important catalytic roles in organic transformations [195,196], and the catalytic cycles involving Lewis acids resemble coordination catalysis processes (Fig. 9(a)). Especially, solid Lewis acids exhibit interesting catalytic behaviors in the activation of carbonyl groups in the polar solvent. Roman-Leshkov et al. [197] have presented an elegant review article on this important topic and the activation of carbonyl groups generally start from the formation of carbonyl complex via different Lewis acid-base interactions (Fig. 9(b)). It is well known that zeolites with coordinatively unsaturated cations in the framework positions are unique water-tolerant Lewis acids, and in this section, we will briefly discuss their catalytic applications in the activation of carbonyl-containing molecules using Baeyer-Villiger oxidation rearrangement and Meerwein-Ponndorf-Verley reduction as examples.

\subsubsection{Baeyer-Villiger oxidation rearrangement}

The Baeyer-Villiger (B-V) oxidation rearrangement reaction, first reported in 1899, has been widely used in the conversion of ketones into more valuable esters and lactones [198]. Since strong oxidants (hydrogen peroxide or alkyl peroxide) are employed in B-V oxidation rearrangement reactions, traditional catalysts could also catalyze the oxidation of other functional groups like $\mathrm{C}=\mathrm{C}$ double bonds in the ketone substrates, result- (a)

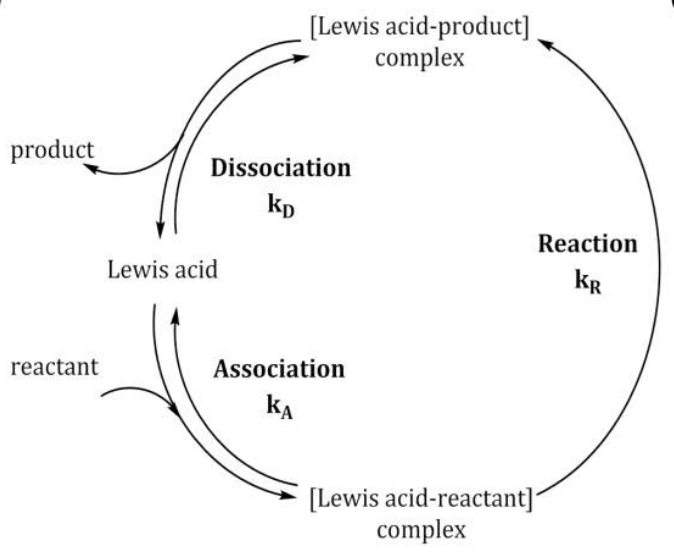

(b)
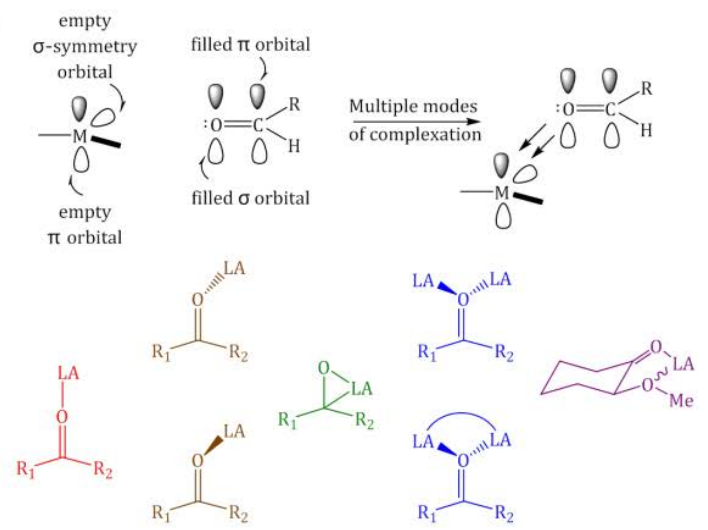

Electrostatic interaction $\sigma$-bonding coordination through double coordination chelation

Fig. 9. (a) The representative catalytic cycle using Lewis acid catalyst; (b) The complexation between Lewis acids and carbonyl compounds, reproduced from Ref. [197] with permission. 
ing in low selectivity toward desired products. Bhaumik et al. [199] first reported the use of TS- 1 to catalyze B-V oxidation rearrangement reaction in 1996 . With $\mathrm{H}_{2} \mathrm{O}_{2}$ as oxidant, peroxide Ti species was generated on the TS-1 catalyst to oxidize cyclohexanone and acetophenone substrates to corresponding esters with considerable yields. The acidic nature of Ti peroxo species was proposed to be responsible for the formation of byproducts such as hydroxyl compounds and diketones. In 2001, a breakthrough of B-V oxidation rearrangement reaction was made by Corma et al. [200] with the use of aluminum-free Sn-beta as a heterogeneous catalyst. It was reported that Sn-beta could catalyze the B-V oxidation rearrangement of unsaturated ketones with good selectivity toward the corresponding esters or lactones $\left(\mathrm{H}_{2} \mathrm{O}_{2}\right.$ as an oxidant). A new catalytic mechanism was also proposed for the B-V oxidation catalyzed by Sn-beta with hydrogen peroxide, including the coordination of ketone to Lewis acid center, the attack of $\mathrm{H}_{2} \mathrm{O}_{2}$ toward more electrophilic carbonyl carbon atom, the rearrangement step and the replacement of lactone by a new substrate molecule. Later on, Corma et al. [201] found that there were two types of active Sn sites in Sn-beta zeolite, namely, partially hydrolyzed skeleton Sn sites (-Si-O- $)_{3} \mathrm{Sn}-\mathrm{OH}$ and fully coordinated skeleton $\mathrm{Sn}$ sites (-Si-O-) 4 Sn. The partially hydrolyzed Sn sites exhibited higher activity in cyclohexanone conversion to $\varepsilon$-caprolactone than the fully coordinated ones. Zhang et al. [55] developed a steam-assisted conversion method to prepare Sn-beta zeolite for the B-V oxidation of cyclohexanone to $\varepsilon$-caprolactone. The formation of polymerized hexa-coordinated Sn-O-Sn species and/or amorphous phase, which were not good for B-V oxidation reaction, could be efficiently suppressed through the steam-assisted conversion method.

\subsubsection{Meerwein-Ponndorf-Verley reduction}

The Meerwein-Ponndorf-Verley (MPV) reduction was discovered by Meerwein et al. [202] and separately by Verley [203] in 1925, and further upgraded by Ponndorf [204]. Alcohol is used as the sacrificial reducing agent to selectively reduce the $\mathrm{C}=\mathrm{O}$ double bond of carbonyl under mild conditions, probably via direct hydride transfer. MPV reduction shows high chemoselectivity and, for example, it can be applied to the hydrogenation of the carbonyl in $\alpha, \beta$-unsaturated aldehyde/ketone with the preservation of $\mathrm{C}=\mathrm{C}$ bond.

Aluminium alkoxide is the initial catalyst employed in MPV reduction and many homogeneous Lewis acids are found to be active for this type of reactions. In this context, zeolites with coordinatively unsaturated cations in the framework positions might be potential catalysts. Corma et al. [205] employed Sn-beta zeolite to catalyze the MPV reduction of aldehydes and ketones by alcohols, and the expected good catalytic activity was achieved. Compared with other framework atoms such as $\mathrm{Ti}$ and $\mathrm{Al}, \mathrm{Sn}$ atoms possess higher electronegativity, which makes Sn-beta a stronger solid Lewis acid and more suitable for MPV reduction. The catalytic activity of Sn-beta zeolite is also highly dependent on the aldehyde/ketone substrates and alcohol reductants. For example, very high activity could be achieved with Sn-beta zeolite in the MPV reduction of cyclo- hexanone by 2-butanol [206].

Similar to Sn-zeolites, Zr-zeolites, with coordinatively unsaturated $\mathrm{Zr}$ sites and resulting Lewis acidity, show high catalytic activity as well as good selectivity in the reactions of MPV reduction. Jaenicke et al. [207] synthesized Al-free Zr-beta with $\mathrm{Zr}$ content of $1.3 \mathrm{wt} \%$ and successfully applied it in the MPV reduction of different alkyl cyclohexanones. A distinct advantage of Zr-beta over homogeneous Lewis acids and other catalysts was that its catalytic activity could be well preserved in the presence of a large amount of water ( $9 \mathrm{wt} \%$ ), and even pyridine showed little impact on its catalytic activity. Ivanova et al. [208] prepared a series of Zr-containing samples to catalyze the MPV reduction of crotonaldehyde to crotyl alcohol and Zr-BEA was found to be most active. The specific MPV activity of Zr-containing samples correlated well with the amount of $\mathrm{Zr}^{4+}$ Lewis acid sites, revealing the key role of these sites in MPV reduction.

\section{Concluding remarks}

Zeolites are known as the most important catalytic materials in the petrochemical industry, and the traditional catalytic applications of zeolites, such as cracking, isomerization and alkylation, mainly rely on their Brønsted acidity and sometimes shape selectivity from their channel systems. On the other hand, zeolites with ordered porous structure of molecular size are ideal scaffold that can accommodate a variety of cations. With coordinatively unsaturated cation sites introduced into zeolite matrix, bifunctional or multifunctional zeolite-based catalysts can be constructed, which are especially suitable for complicated reactions such as SCR and $\mathrm{C}-\mathrm{H}$ bond activation. Since the coordinatively unsaturated cation sites play key roles in these reactions, the catalytic active sites can be well explained from the view of coordination chemistry and the reactions resemble homogeneous coordination catalysis. During the past decades, significant achievements have been made on the construction, characterization and catalytic applications of coordinatively unsaturated sites in zeolite matrix. However, some issues are still to be solved and challenges do exist.

Many strategies have been developed to introduce cations into zeolite matrix, for example the simple ion-exchange, the diffusion impregnation, the direct hydrothermal synthesis, the encapsulation of complexes and post-synthesis modifications. Highly dispersed cations at both zeolite framework and extraframework positions are desired and the formation of aggregates on the outer surface of zeolite should be avoided as much as possible. Generally, the direct hydrothermal synthesis and post-synthesis modifications can lead to cations incorporated into zeolite framework, while other strategies lead to cations at extraframework positions. The obtained cations may exist in coordinatively unsaturated states and, more likely, in the saturated states that are thermodynamically more stable. In the latter case, suitable post-treatment activation processes are needed to obtain the coordinatively unsaturated cation sites for catalytic applications. Though various cations can be easily introduced into zeolite matrix, it is extremely difficult to obtain the so-called single cation sites at extraframework positions, 
making the subsequent characterization and catalytic studies more difficult.

The identification and characterization of cation sites are generally difficult, especially with the influence or even disturbance from zeolite hosts. A series of spectroscopic techniques, including vibrational spectroscopy (FTIR and Raman), electronic spectroscopy (UV-vis-DRS and XPS), spin resonance spectroscopy (NMR and EPR) and X-ray absorption spectroscopy, have been employed in the characterization of cation sites in zeolite matrix, and each technique is good at something. To obtain clear information on the existing states of cation sites in zeolite matrix, the combination of two or more spectroscopic techniques are required and the theoretical simulations should be a fine addition. A key challenge in the characterization of cations sites comes from the dynamic behaviors of these sites. There is no doubt that the coordination states of active cation sites undergo periodic changes during catalytic reactions, especially in coordination catalysis. To solve the problem, in situ spectroscopy should be helpful and operando spectroscopy with the simultaneous measurements of the transient spectra and kinetic data should be better. However, the successful applications of in situ or operando spectroscopy are restricted by the intrinsic characters of spectroscopic techniques such as the signal and time resolution.

Zeolites with coordinatively unsaturated sites are widely used as catalysts in various important reactions, from environmental catalysis to energy catalysis and from petrochemical industry to fine chemistry. Some of these reactions, such as $\mathrm{NH}_{3}$-SCR catalyzed by Fe-zeolites and $\mathrm{Cu}$-zeolites, olefin epoxidation catalyzed by Ti-zeolites, have been successfully commercialized, while others are still on the way. Zeolite hosts can provide necessary coordination environment for guest cations to produce the catalytically active sites for specific reactions. Meanwhile, the functionalities of zeolite hosts, for example the acid-base properties and shape-selectivity, can be utilized to construct bifunctional or multifunctional catalysts for more complicated reactions. The limited space makes it difficult to construct multifunctional centers within zeolite matrix. However, the limited space is good to realize the processes of coop- erative catalysis or relay catalysis. With the delicate design of coordinatively unsaturated sites in zeolite matrix, the selective transformation of chemicals can be expected. Understanding the mechanism and structure-activity relationship is always a challenging topic in catalysis studies, and this is even more challenging with coordinatively unsaturated sites in zeolite matrix as complicated catalyst systems. If well-defined single cation site in zeolite matrix can be constructed, it can be treated like an organometallic complex (zeolite as the ligand of central cation) and the reaction mechanism can be more clearly understood.

\section{References}

[1] J. N. Armor, Catal. Today, 2011, 163, 3-9.

[2] C. Perego, A. Carati, in: J. Cejka, J. Peréz-Pariente, W.J. Roth (Eds.), Zeolites: From Model Materials to Industrial Catalysts, Transworld Research Network, Kerala, 2008, 357.

[3] A. Corma, M. J. Diaz-Cabañas, J. Martínez-Triguero, F. Rey, J. Rius, Nature, 2002, 418, 514-517.

[4] F. Basolo, R. C. Johnso, Coordination Chemistry. Science Reviews, Wilmington, DE, 1986.

[5] P. A. Chaloner, Handbook of Coordination Catalysis in Organic Chemistry, Butterworths, London, 1986.

[6] G. Henrici-Olivé, S. Olivé. Coordination and Catalysis, Vol. 9, Verlag Chemie, Weinheim. NewYork, 1977.

[7] G. Natta, P. Pino, G. Mazzanti, U. Giannini, E. Mantica, M. Peraldo, J. Polym. Sci., 1957, 26, 120-123.

[8] J. Smidt, W. Hafner, R. Jira, R. Sieber, J. Sedlmeier, A. Sabel, Angew. Chem., 1962, 74, 93-102.

[9] D. Forster, J. Am. Chem. Soc., 1976, 98, 846-848.

[10] B. Tang, W. Dai, X. Sun, N. Guan, L. Li, M. Hunger, Green Chem., 2014, 16, 2281-2291.

[11] B. Tang, W. Dai, X. Sun, G. Wu, N. Guan, M. Hunger, L. Li, Green Chem. 2015, 17, 1744-1755.

[12] J. Dwyer, K. Karim, J. Chem. Soc. Chem. Commun., 1991, 905-906.

[13] W. Kim, J. So, S. W. Choi, Y. Liu, R. S. Dixit, C. Sievers, D. S. Sholl, S. Nair, C. W. Jones, Chem. Mater., 2017, 29, 7213-7222.

[14] B. Tang, W. Dai, G. Wu, N. Guan, L. Li, M. Hunger, ACS Catal., 2014, 4, 2801-2810.

[15] A. A. Verberckmoes, B. M. Weckhuysen, R. A. Schoonheydt, Mi-

\section{Graphical Abstract}

Chin. J. Catal., 2019, 40: 1255-1281 doi: S1872-2067(19)63381-4

\section{Coordinatively unsaturated sites in zeolite matrix: Construc- tion and catalysis}

Weijie Li, Lanan Sun, Linjun Xie, Xin Deng, Naijia Guan,

Landong $\mathrm{Li}^{*}$

Nankai University

This review presents the recent progresses on the construction, characterization and catalytic applications of coordinatively unsaturated sites in zeolite matrix from the specific view of coordination chemistry.

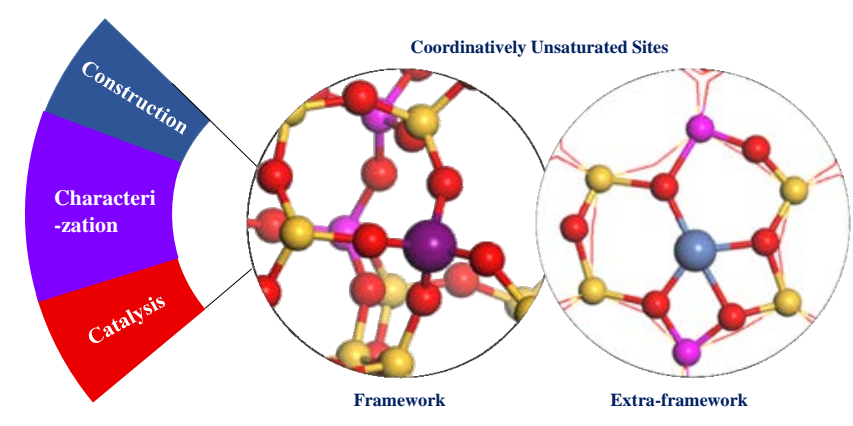


croporous Mesoporous Mater., 1998, 22, 165-178.

[16] P. Vanelderen, J. Vancauwenbergh, B. F. Sels, R. A. Schoonheydt, Coord. Chem. Rev., 2013, 257, 483-494.

[17] J. S. Woertink, P. J. Smeets, M. H. Groothaert, M. A. Vance, B. F. Sels, R. A. Schoonheydt, E. I. Solomon, Proc. Natl. Acad. Sci. U.S.A., 2009, 106, 18908-18913.

[18] M. H. Mahyuddin, A. Staykov, Y. Shiota, M. Miyanishi, K. Yoshizawa, ACS Catal., 2017, 7, 3741-3751.

[19] G. Turnes Palomino, S. Bordiga, A. Zecchina, G. L. Marra, C. Lamberti, J. Phys. Chem. B, 2000, 104, 8641-8651.

[20] T. Ryu, N. H. Ahn, S. Seo, J. Cho, H. Kim, D. Jo, G. T. Park, P. S. Kim, C. H. Kim, E. L. Bruce, P. A. Wright, I. S. Nam, S. B. Hong, Angew. Chem. Int. Ed., 2017, 56, 3256-3260.

[21] C. Lamberti, S. Bordiga, A. Zecchina, M. Salvalaggio, F. Geobaldo, C. Otero Areán, J. Chem. Soc. - Faraday Trans., 1998, 94, 1519-1525.

[22] C. Chupin, A. C. van Veen, M. Konduru, J. Després, C. Mirodatos, J. Catal., 2006, 241, 103-114.

[23] Y. Li, T. L. Slager, J. N. Armor, J. Catal., 1994, 150, 388-399.

[24] D. Kaucký, J. Dědeček, B. Wichterlová, Microporous Mesoporous Mater., 1999, 31, 75-87.

[25] X. Guo, L. Wu, A. Navrotsky, Phys. Chem. Chem. Phys., 2018, 20, 3970-3978.

[26] M. Mihaylov, K. Hadjiivanov, D. Panayotov, Appl. Catal. B, 2004, 51, 33-42.

[27] A. Penkova, S. Dzwigaj, R. Kefirov, K. Hadjiivanov, M. Che, J. Phys. Chem. C, 2007, 111, 8623-8631.

[28] H. A. Aleksandrov, V. R. Zdravkova, M. Y. Mihaylov, P. S. Petkov, G. N. Vayssilov, K. I. Hadjiivanov, J. Phys. Chem. C, 2012, 116, 22823-22831.

[29] F. Gao, Y. Zheng, R. K. Kukkadapu, Y. Wang, E. D. Walter, B. Schwenzer, J. Szanyi, C. H. F. Peden, ACS Catal., 2016, 6, 2939-2954.

[30] J. Dědeček, Z. Sobalík, B. Wichterlová, Catal. Rev. Sci. Eng., 2012, 54, 135-223.

[31] A. V. Kucherov, A. A. Slinkin, Zeolites, 1987, 7, 38-42.

[32] S. H. Choi, B. R. Wood, J. A. Ryder, A. T. Bell, J. Phys. Chem. B, 2003, 107, 11843-11851.

[33] C. Hammond, N. Dimitratos, R. L. Jenkins, J. A. Lopez-Sanchez, S. A. Kondrat, M. Hasbi Ab Rahim, M. M. Forde, A. Thetford, S. H. Taylor, H. Hagen, E. E. Stangland, J. H. Kang, J. M. Moulijn, D. J. Willock, G. J. Hutchings, ACS Catal., 2013, 3, 689-699.

[34] S. Shwan, M. Skoglundh, L. F. Lundegaard, R. R. Tiruvalam, T. V. W. Janssens, A. Carlsson, P. N. R. Vennestrøm, ACS Catal., 2015, 5, 16-19.

[35] C. Lamberti, S. Bordiga, M. Salvalaggio, G. Spoto, A. Zecchina, F. Geobaldo, G. Vlaic, M. Bellatreccia, J. Phys. Chem. B, 1997, 101, 344-360.

[36] G. Spoto, A. Zecchina, S. Bordiga, G. Ricchiardi, G. Martra, G. Leofanti, G. Petrini, Appl. Catal. B, 1994, 3, 151-172.

[37] M. L. Bols, S. D. Hallaert, B. E. R. Snyder, J. Devos, D. Plessers, H. M. Rhoda, M. Dusselier, R. A. Schoonheydt, K. Pierloot, E. I. Solomon, B. F. Sels, J. Am. Chem. Soc., 2018, 140, 12021-12032.

[38] B. E. R. Snyder, P. Vanelderen, M. L. Bols, S. D. Hallaert, L. H. Böttger, L. Ungur, K. Pierloot, R. A. Schoonheydt, B. F. Sels, E. I. Solomon, Nature, 2016, 536, 317-321.

[39] J. Long, X. Wang, Z. Ding, Z. Zhang, H. Lin, W. Dai, X. Fu, J. Catal., 2009, 264, 163-174.

[40] G. Wu, F. Hei, N. Zhang, N. Guan, L. Li, W. Grünert, Appl. Catal. A, 2013, 468, 230-239.

[41] G. Wu, N. Zhang, W. Dai, N. Guan, L. Li, ChemSusChem, 2018, 11, 2179-2188.

[42] G. Perego, M. Taramasso, B. Notari, US Patent 4410 501, 1983.
[43] J. S. Reddy, R. Kumar, P. Ratnasamy, Appl. Catal., 1990, 58, L1-L4.

[44] A. Tuel, Zeolites, 1995, 15, 236-242.

[45] A. Tuel, Zeolites, 1995, 15, 228-235.

[46] E. Gianotti, A. Frache, S. Coluccia, J. M. Thomas, T. Maschmeyer, L. Marchese, J. Mol. Catal. A, 2003, 204-205, 483-489.

[47] H.-J. Chae, S. S. Park, Y. H. Shin, M. B. Park, Microporous Mesoporous Mater., 2018, 259, 60-66.

[48] A. Corma, P. Esteve, A. Martínez, J. Catal., 1996, 161, 11-19.

[49] T. Blasco, M. A. Camblor, A. Corma, P. Esteve, J. M. Guil, A. Martínez, J. A. Perdigón-Melón, S. Valencia, J. Phys. Chem. B, 1998, 102, 75-88.

[50] P. Wu, T. Tatsumi, T. Komatsu, T. Yashima, J. Phys. Chem. B, 2001, 105, 2897-2905.

[51] G. M. Lari, C. Mondelli, J. Pérez-Ramírez, ACS Catal., 2015, 5, 1453-1461.

[52] R. Szostak, V. Nair, T. L. Thomas, J. Chem. Soc. Faraday Trans. 1, 1987, 83, 487.

[53] T. Tatsumi, N. Jappar, J. Phys. Chem. B, 1998, 102, 7126-7131.

[54] Z. Kang, X. Zhang, H. Liu, J. Qiu, W. Han, K. L. Yeung, Mater. Chem. Phys., 2013, 141, 519-529.

[55] Z. Kang, X. Zhang, H. Liu, J. Qiu, K. L. Yeung, Chem. Eng. J., 2013, 218, 425-432.

[56] P. Y. Dapsens, C. Mondelli, J. Pérez-Ramírez, Chem. Soc. Rev., 2015 44, 7025-7043.

[57] L. Ren, L. Zhu, C. Yang, Y. Chen, Q. Sun, H. Zhang, C. Li, F. Nawaz, X. Meng, F. S. Xiao, Chem. Commun., 2011, 47, 9789-9791.

[58] M. Shen, X. Li, J. Wang, C. Wang, J. Wang, Ind. Eng. Chem. Res., 2018, 57, 3501-3509.

[59] Z. Chen, C. Fan, L. Pang, S. Ming, W. Guo, P. Liu, H. Chen, T. Li, Chem. Eng. J., 2018, 348, 608-617.

[60] S.J. Jong, S. Cheng, Appl. Catal. A, 1995, 126, 51-66.

[61] L. Meng, X. Zhu, E. J. M. Hensen, ACS Catal., 2017, 7, 2709-2719.

[62] E. Yuan, G. Wu, W. Dai, N. Guan, L. Li, Catal. Sci. Technol., 2017, 7, 3036-3044.

[63] S. Han, Q. Wu, W. Chen, J. Zhang, L. Wang, L. Zhu, A. Zheng, C. Jin, X. Meng, F. S. Xiao, ACS Appl. Mater. Interfaces, 2018, 10, 33214-33220.

[64] E. Yuan, W. Dai, G. Wu, N. Guan, M. Hunger, L. Li, Microporous Mesoporous Mater., 2018, 270, 265-273.

[65] A. Kozlov, K. Asakura, Y. Iwasawa, J. Chem. Soc. - Faraday Trans., 1998, 94, 809-816.

[66] T. M. Salama, A. H. Ahmed, Z. M. El-Bahy, Microporous Mesoporous Mater., 2006, 89, 251-259.

[67] A. A. Valente, J. Vital, J. Mol. Catal. A, 2000, 156, 163-172.

[68] N. Herron, Inorg. Chem., 1986, 25, 4714-4717.

[69] B. Dutta, S. Jana, R. Bera, P. K. Saha, S. Koner, Appl. Catal. A, 2007, 318, 89-94.

[70] R. M. Barrer, Hydrothermal Chemistry of Zeolites, Academic Press, London, 1982.

[71] J.-P. Nogier, Y. Millot, P. P. Man, T. Shishido, M. Che, S. Dzwigaj, J. Phys. Chem. C, 2009, 113, 4885-4889.

[72] T. Maschmeyer, F. Rey, G. Sankar, J. M. Thomas, Nature, 1995, 378, 159-162.

[73] A. Corma, U. Díaz, V. Fornés, J. L. Jordá, M. Domine, F. Rey, Chem. Commun., 1999, 779-780.

[74] M. Guidotti, N. Ravasio, R. Psaro, G. Ferraros, G. Moretti, J. Catal., 2003, 214, 242-250.

[75] C. Hammond, S. Conrad, I. Hermans, Angew. Chem. Int. Ed., 2012, 51, 11736-11739.

[76] B. Tang, W. Dai, X. Sun, G. Wu, L. Li, N. Guan, M. Hunger, Chin. J. Catal., 2015, 36, 801-805.

[77] Y. Chai, L. Xie, Z. Yu, W. Dai, G. Wu, N. Guan, L. Li, Microporous 
Mesoporous Mater., 2018, 264, 230-239.

[78] S. Song, G. Wu, W. Dai, N. Guan, L. Li, Catal. Sci. Technol., 2016, 6, 8325-8335.

[79] S. Dzwigaj, M. Che, J. Phys. Chem. B, 2006, 110, 12490-12493.

[80] F. Tielens, M. Trejda, M. Ziolek, S. Dzwigaj, Catal. Today, 2008, 139, 221-226.

[81] K. Hadjiivanov, A. Penkova, R. Kefirov, S. Dzwigaj, M. Che, Microporous Mesoporous Mater., 2009, 124, 59-69.

[82] F. Tielens, T. Shishido, S. Dzwigaj, J. Phys. Chem. C, 2010, 114, 9923-9930.

[83] R. Baran, F. Averseng, Y. Millot, T. Onfroy, S. Casale, S. Dzwigaj, J. Phys. Chem. C, 2014, 118, 4143-4150.

[84] S. Dzwigaj, Y. Millot, J.-M. Krafft, N. Popovych, P. Kyriienko, J. Phys. Chem. C, 2013, 117, 12552-12559.

[85] S. Dzwigaj, Y. Millot, M. Che, Catal. Lett., 2010, 135, 169-174.

[86] R. Baran, L. Valentin, S. Dzwigaj, Phys. Chem. Chem. Phys., 2016, 18, 12050-12057.

[87] S. Song, L. Di, G. Wu, W. Dai, N. Guan, L. Li, Appl. Catal. B, 2017, 205, 393-403.

[88] M. A. Camblor, A. Corma, J. Pérez-Pariente, J. Chem. Soc., Chem. Commun., 1993, 557-559.

[89] Y. Ju, Z. Shen, J. Zhao, J. Zhao, X. Wang, Acta Phys. Chim. Sin., 2006, 22, 28-32.

[90] T. D. Courtney, C. C. Chang, R. J. Gorte, R. F. Lobo, W. Fan, V. Nikolakis, Microporous Mesoporous Mater., 2015,210, 69-76.

[91] V. L. Sushkevich, D. Palagin, I. I. Ivanova, ACS Catal., 2015, 5, 4833-4836.

[92] J. Szanyi, J. H. Kwak, H. Zhu, C. H. F. Peden, Phys. Chem. Chem. Phys., 2013, 15, 2368-2380.

[93] K. Hadjiivanov, H. Knözinger, J. Catal., 2000, 191, 480-485.

[94] A. Bellmann, H. Atia, U. Bentrup, A. Brückner, Appl. Catal. B, 2018, 230, 184-193.

[95] R. Kefirov, E. Ivanova, K. Hadjiivanov, S. Dzwigaj, M. Che, Catal. Lett., 2008, 125, 209-214.

[96] A. Zecchina, M. Rivallan, G. Berlier, C. Lamberti, G. Ricchiardi, Phys. Chem. Chem. Phys., 2007, 9, 3483-3499.

[97] A. M. Beale, F. Gao, I. Lezcano-Gonzalez, C. H. F. Peden, J. Szanyi, Chem. Soc. Rev., 2015, 44, 7371-7405.

[98] F. Göltl, P. Sautet, I. Hermans, Angew. Chem. Int. Ed., 2015, 54, 7799-7804

[99] A. Aziz, M. Sajjad, M. Kim, K. S. Kim, Int. J. Environ. Sci. Technol., 2018, 15, 707-718.

[100] C. L. Angell, J. Phys. Chem., 1973, 77, 222-227.

[101] C. Li, G. Xiong, Q. Xin, J. Liu, P. L. Ying, Z. C. Feng, J. Li, W. B. Yang, Y. Z. Wang, G. R. Wang, X. Y. Liu, M. Lin, X. Q. Wang, E. Z. Min, Angew. Chem. Int. Ed., 1999, 38, 2220-2222.

[102] Y. Yu, G. Xiong, C. Li, F. S. Xiao, J. Catal., 2000, 194, 487-490.

[103] R. Bermejo-Deval, R. Gounder, M. E. Davis, ACS Catal., 2012, 2, 2705-2713.

[104] D. Srinivas, R. Srivastava, P. Ratnasamy, Catal. Today, 2004, 96, 127-133.

[105] A. Corma, M. A. Camblor, P. Esteve, A. Martínez, J. Pérez-Pariente, J. Catal., 1994, 145, 151-158.

[106] S. T. Korhonen, D. W. Fickel, R. F. Lobo, B. M. Weckhuysen, A. M. Beale, Chem. Commun., 2011, 47, 800-802.

[107] R. A. Schoonheydt, J. Phys. Chem. Solids, 1989, 50, 523-539.

[108] H. Y. Zheng, J. Z. Wang, Z. Li, L. F. Yan, J. Z. Wen, Fuel Process. Technol., 2016, 152, 367-374.

[109] R. Bermejo-Deval, R. S. Assary, E. Nikolla, M. Moliner, Y. Roman-Leshkov, S.-J. Hwang, A. Palsdottir, D. Silverman, R. F. Lobo, L. A. Curtiss, M. E. Davis, Proc. Natl. Acad. Sci. U.S.A., 2012, 109, 9727-9732.
[110] M. Renz, T. Blasco, A. Corma, V. Fornés, R. Jensen, L. Nemeth, Chem. Eur. J., 2002, 8, 4708-4717.

[111] W. R. Gunther, V. K. Michaelis, M. A. Caporini, R. G. Griffin, Y. Román-Leshkov, J. Am. Chem. Soc., 2014, 136, 6219-6222.

[112] Y. G. Kolyagin, A. V. Yakimov, S. Tolborg, P. N. R. Vennestrøm, I. I. Ivanova, J. Phys. Chem. Lett., 2016, 7, 1249-1253.

[113] Y. G. Kolyagin, A. V. Yakimov, S. Tolborg, P. N. R. Vennestrøm, I. I. Ivanova, J. Phys. Chem. Lett., 2018, 9, 3738-3743.

[114] A. V. Kucherov, A. A. Slinkin, D. A. Kondrat'ev, T. N. Bondarenko, A. M. Rubinstein, K. M. Minachev, Zeolites, 1985, 5, 320-324.

[115] L. E. Iton, I. Choi, J. A. Desjardins, V. A. Maroni, Zeolites, 1989, 9, 535-538.

[116] M. Zamadics, X. Chen, L. Kevan, J. Phys. Chem., 1992, 96, 5488-5491.

[117] J. Xue, X. Wang, G. Qi, J. Wang, M. Shen, W. Li, J. Catal., 2013, 297, 56-64.

[118] R. G. Herman, D. R. Flentge, J. Phys. Chem., 1978, 82, 720-729.

[119] P. J. Smeets, J. S. Woertink, B. F. Sels, E. I. Solomon, R. A. Schoonheydt, Inorg. Chem., 2010, 49, 3573-3583.

[120] A. A. Gabrienko, S. S. Arzumanov, A. V. Toktarev, I. G. Danilova, I. P. Prosvirin, V. V. Kriventsov, V. I. Zaikovskii, D. Freude, A. G. Stepanov, ACS Catal., 2017, 7, 1818-1830.

[121] M. Sano, T. Maruo, H. Yamatera, M. Suzuki, Y. Saito, J. Am. Chem. Soc., 1987, 109, 52-55.

[122] S. Bordiga, R. Buzzoni, F. Geobaldo, C. Lamberti, E. Giamello, A. Zecchina, G. Leofanti, G. Petrini, G. Tozzola, G. Vlaic, J. Catal., 1996, 158, 486-501.

[123] M. H. Groothaert, J. A. van Bokhoven, A. A. Battiston, B. M. Weckhuysen, R. A. Schoonheydt, J. Am. Chem. Soc., 2003, 125, 7629-7640.

[124] S. R. Bare, S. D. Kelly, W. Sinkler, J. J. Low, F. S. Modica, S. Valencia, A. Corma, L. T. Nemeth, J. Am. Chem. Soc., 2005, 127, 12924-12932.

[125] G. Ricchiardi, A. Damin, S. Bordiga, C. Lamberti, G. Spanò, F. Rivetti, A. Zecchina, J. Am. Chem. Soc., 2001, 123, 11409-11419.

[126] D. K. Pappas, E. Borfecchia, M. Dyballa, I. A. Pankin, K. A. Lomachenko, A. Martini, M. Signorile, S. Teketel, B. Arstad, G. Berlier, C. Lamberti, S. Bordiga, U. Olsbye, K. P. Lillerud, S. Svelle, P. Beato, J. Am. Chem. Soc., 2017, 139, 14961-14975.

[127] S. Bordiga, E. Groppo, G. Agostini, J. A. van Bokhoven, C. Lamberti, Chem. Rev., 2013, 113, 1736-1850.

[128] G. Berlier, G. Spoto, S. Bordiga, G. Ricchiardi, P. Fisicaro, A. Zecchina, I. Rossetti, E. Selli, L. Forni, E. Giamello, C. Lamberti, J. Catal., 2002, 208, 64-82.

[129] J. Wang, H. Chen, Z. Hu, M. Yao, Y. Li, Catal. Rev., 2015, 57, 79-144.

[130] R. Zhang, N. Liu, Z. Lei, B. Chen, Chem. Rev., 2016, 116, 3658-3721.

[131] M. Iwamoto, H. Furukawa, Y. Mine, F. Uemura, S. Mikuriya, S. Kagawa, J. Chem. Soc. Chem. Commun., 1986, 1272-1273.

[132] J. H. Kwak, R. G. Tonkyn, D. H. Kim, J. Szanyi, C. H. F. Peden, J. Catal., 2010, 275, 187-190.

[133] I. Lezcano-Gonzalez, U. Deka, B. Arstad, A. Van Yperen-De Deyne, K. Hemelsoet, M. Waroquier, V. Van Speybroeck, B. M. Weckhuysen, A. M. Beale, Phys. Chem. Chem. Phys., 2014, 16, 1639-1650.

[134] J. Wang, H. Zhao, G. Haller, Y. Li, Appl. Catal. B, 2017, 202, 346-354.

[135] F. Gao, D. Mei, Y. Wang, J. Szanyi, C. H. F. Peden, J. Am. Chem. Soc., 2017, 139, 4935-4942.

[136] S. Brandenberger, O. Kröcher, A. Tissler, R. Althoff, Catal. Rev. Sci. 
Eng., 2008, 50, 492-531.

[137] P. Boroń, M. Rutkowska, B. Gil, B. Marszałek, L. Chmielarz, S. Dzwigaj, ChemSusChem, 2019, 12, 692-705.

[138] M. Shelef, Chem. Rev., 1995, 95, 209-225.

[139] Y. Li, J. N. Armor, Appl. Catal. B, 1993, 2, 239-256.

[140] Y. Li, J. N. Amor, Stud. Surf. Sci. Catal., 1994, 81, 103-113.

[141] M. C. Campa, S. De Rossi, G. Ferraris, V. Indovina, Appl. Catal. B, 1996, 8, 315-331.

[142] M. C. Campa, V. Indovina, J. Porous Mater., 2007, 14, 251-261.

[143] D. Kaucký, A. Vondrová, J. Dědeček, B. Wichterlová, J. Catal., 2000, 194, 318-329.

[144] J. M. Thomas, R. Raja, G. Sankar, R. G. Bell, Nature, 1999, 398, 227-230.

[145] M. Dugal, G. Sankar, R. Raja, J. M. Thomas, Angew. Chem. Int. Ed., 2000, 39, 2310-2313.

[146] R. Raja, G. Sankar, J. M. Thomas, J. Am. Chem. Soc., 1999, 121, 11926-11927.

[147] W. Taifan, J. Baltrusaitis, Appl. Catal. B, 2016, 198, 525-547.

[148] M. H. Groothaert, P. J. Smeets, B. F. Sels, P. A. Jacobs, R. A. Schoonheydt, J. Am. Chem. Soc., 2005, 127, 1394-1395.

[149] R. Balasubramanian, S. M. Smith, S. Rawat, L. A. Yatsunyk, T. L. Stemmler, A. C. Rosenzweig, Nature, 2010, 465, 115-119.

[150] S. Grundner, M. A. C. Markovits, G. Li, M. Tromp, E. A. Pidko, E. J. M. Hensen, A. Jentys, M. Sanchez-Sanchez, J. A. Lercher, Nat. Commun., 2015, 6, 7546.

[151] V. L. Sushkevich, D. Palagin, M. Ranocchiari, J. A. van Bokhoven, Science, 2017, 356, 523-527.

[152] B. E. R. Snyder, P. Vanelderen, R. A. Schoonheydt, B. F. Sels, E. I. Solomon, J. Am. Chem. Soc., 2018, 140, 9236-9243.

[153] B. E. R. Snyder, L. H. Böttger, M. L. Bols, J. J. Yan, H. M. Rhoda, A. B. Jacobs, M. Y. Hu, J. Zhao, E. E. Alp, B. Hedman, K.O. Hodgson, R.A. Schoonheydt, B. F. Sels, E. I. Solomon, Proc. Natl. Acad. Sci. U.S.A., 2018, 115, 4565-4570.

[154] B. E. R. Snyder, M. L. Bols, R. A. Schoonheydt, B. F. Sels, E. I. Solomon, Chem. Rev., 2018, 118, 2718-2768.

[155] C. Hammond, M. M. Forde, M. H. Ab Rahim, A. Thetford, Q. He, R. L. Jenkins, N. Dimitratos, J. A. Lopez-Sanchez, N. F. Dummer, D. M. Murphy, A. F. Carley, S. H. Taylor, D. J. Willock, E. E. Stangland, J. Kang, H. Hagen, C. J. Kiely, G. J. Hutchings, Angew. Chem. Int. Ed., 2012, 51, 5129-5133.

[156] K. S. Pillai, J. Jia, W. M. H. Sachtler, Appl. Catal. A, 2004, 264, 133-139.

[157] G. Berlier, F. Bonino, A. Zecchina, S. Bordiga, C. Lamberti, ChemPhysChem, 2003, 4, 1073-1078.

[158] J. Pérez-Ramírez, A. Gallardo-Llamas, J. Catal., 2004, 223, 382-388.

[159] E. V. Kondratenko, J. Pérez-Ramírez, Appl. Catal. A, 2004, 267, 181-189.

[160] J. Pérez-Ramírez, A. Gallardo-Llamas, Appl. Catal. A, 2005, 279, 117-123.

[161] O. Sánchez-Galofré, Y. Segura, J. Pérez-Ramírez, J. Catal., 2007, 249, 123-133.

[162] J. Pérez-Ramírez, A. Gallardo-Llamas, J. Phys. Chem. B, 2005, 109, 20529-20538.

[163] G. Wu, F. Hei, N. Guan, L. Li, Catal. Sci. Technol., 2013, 3, 1333-1342.

[164] G. Wu, Y. Hao, N. Zhang, N. Guan, L. Li, W. Grünert, Microporous Mesoporous Mater., 2014, 198, 82-91.

[165] R. Bulánek, K. Novoveská, B. Wichterlová, Appl. Catal. A, 2002, 235, 181-191.

[166] Y. Cheng, C. Miao, W. Hua, Y. Yue, Z. Gao, Appl. Catal. A, 2017, 532, 111-119.
[167] J. Janas, J. Gurgul, R. P. Socha, J. Kowalska, K. Nowinska, T. Shishido, M. Che, S. Dzwigaj, J. Phys. Chem. C, 2009, 113, 13273-13281.

[168] Y. Cheng, F. Zhang, Y. Zhang, C. Miao, W. Hua, Y. Yue, Z. Gao, Chin. J. Catal., 2015, 36, 1242-1248.

[169] A. Finiels, F. Fajula, V. Hulea, Catal. Sci. Technol., 2014, 4, 2412-2426.

[170] P. Cossee, J. Catal., 1964, 3, 80-88.

[171] T. Yashima, Y. Ushida, M. Ebisawa, N. Hara, J. Catal., 1975, 36, 320-326.

[172] L. Bonneviot, D. Olivier, M. Che, J. Mol. Catal., 1993, 21, 415-430.

[173] M. Hartmann, L. Kevan, J. Chem. Soc. - Faraday Trans., 1996, 92, 1429-1434.

[174] A. Martínez, M. A. Arribas, P. Concepción, S. Moussa, Appl. Catal. A, 2013, 467, 509-518.

[175] J. R. Sohn, J. H. Park, Appl. Catal. A, 2001, 218, 229-234.

[176] R. Y. Brogaard, U. Olsbye, ACS Catal., 2016, 6, 1205-1214.

[177] S. Moussa, P. Concepción, M. A. Arribas, A. Martínez, ACS Catal., 2018, 8, 3903-3912.

[178] R. A. Sheldon, J. K. Kochi, Metal-Catalyzed Oxidation of Organic Compounds, Academic Press, New York, 1981

[179] Q. Tang, Q. Zhang, H. Wu, Y. Wang, J. Catal., 2005, 230, 384-397.

[180] J. Sebastian, K. M. Jinka, R. V. Jasra, J. Catal., 2006, 244, 208-218.

[181] N. Indictor, W. F. Brill, J. Org. Chem., 1965, 30, 2074-2075.

[182] A. Corma, P. Esteve, A. Martinez, S. Valencia, J. Catal., 1995, 152 , 18-24.

[183] P. Wu, T. Tatsumi, T. Komatsu, T. Yashima, Chem. Lett., 2000, 29, 774-775.

[184] J. C. van der Waal, H. van Bekkum, J. Mol. Catal. A, 1997, 124, 137-146.

[185] J. Přech, Catal. Rev. Sci. Eng., 2018, 60, 71-131.

[186] M. G. Clerici, P. Ingallina, J. Catal., 1993, 140, 71-83.

[187] P. Wu, T. Tatsumi, T. Komatsu, T. Yashima, J. Catal., 2001, 202, 245-255.

[188] S. Rebsdat, D. Mayer, Ethylene Glycol, in: Ullmann's Encycl. Ind. Chem., Wiley-VCH Verlag GmbH \& Co. KGaA, Weinheim, Germany, 2000: p. 44. doi:10.1002/14356007.a10_101.

[189] B. Li, S. Bai, X. Wang, M. Zhong, Q. Yang, C. Li, Angew. Chem. Int. Ed., 2012, 51, 11517-11521.

[190] W. Dai, C. Wang, B. Tang, G. Wu, N. Guan, Z. Xie, M. Hunger, L. Li, ACS Catal., 2016, 6, 2955-2964.

[191] G. Prestat, C. Baylon, M.-P. Heck, C. Mioskowski, Tetrahedron Lett., 2000, 41, 3829-3831.

[192] J. K. Satyarthi, L. Saikia, D. Srinivas, P. Ratnasamy, Appl. Catal. A, 2007, 330, 145-151.

[193] R. Kore, R. Srivastava, B. Satpati, ACS Catal., 2013, 3, 2891-2904.

[194] B. Tang, W. C. Song, S. Y. Li, E. C. Yang, X. J. Zhao, New J. Chem., 2018, 42, 13503-13511.

[195] A. Corma, H. García, Chem. Rev., 2002, 102, 3837-3892.

[196] A. Corma, H. García, Chem. Rev., 2003, 103, 4307-4365.

[197] Y. Román-Leshkov, M. E. Davis, ACS Catal., 2011, 1, 1566-1580.

[198] L. Kürti, B. Czakó, Strategic Applications of Named Reactions in Organic Synthesis, Elsevier Academic Press, Burlington; San Diego; London, 2005, 28.

[199] A. Bhaumik, P. Kumar, R. Kumar, Catal. Lett., 1996, 40, 47-50.

[200] A. Corma, L. T. Nemeth, M. Renz, S. Valencia, Nature, 2001, 412, 423-425.

[201] M. Boronat, P. Concepcion, A. Corma, M. Renz, S. Valencia, J. Catal., 2005, 234, 111-118.

[202] H. Meerwein, R. Schmidt, Justus Liebig's Ann. der Chem., 1925, 444, 221-238.

[203] A. Verley, Bull. Soc. Chim. Fr., 1925, 37, 537-542. 
[204] W. Ponndorf, Angew. Chem., 1926, 39, 138-143.

[205] A. Corma, M. E. Domine, L. Nemeth, S. Valencia, J. Am. Chem. Soc., 2002, 124, 3194-3195.

[206] A. Corma, M. E. Domine, S. Valencia, J. Catal., 2003, 215,
294-304.

[207] Y. Zhu, G. Chuah, S. Jaenicke, J. Catal., 2004, 227, 1-10.

[208] V. L. Sushkevich, I. I. Ivanova, S. Tolborg, E. Taarning, J. Catal., 2014, 316, 121-129.

\title{
沸石分子篮结构内配位不饱和位点：构筑与催化应用
}

\author{
李玮杰, 孙兰兰 ${ }^{\mathrm{a}}$, 谢林君 ${ }^{\mathrm{a}}$, 邓 欣 ${ }^{\mathrm{a}}$, 关乃佳 ${ }^{\mathrm{a}}$, 李兰冬 ${ }^{\mathrm{a}, \mathrm{b}, *}$ \\ a南开大学材料科学与工程学院, 国家先进材料研究所, 天津 300350 \\ $\mathrm{b}$ 南开大学教育部先进能源材料化学重点实验室, 天津 300071
}

\begin{abstract}
摘要: 具有规则微孔结构的沸石分子篮是目前广泛应用的吸附剂和催化剂, 而它的框架结构还可作为承载配位不饱和位 点的理想平台. 近年来, 沸石分子篮结构内配位不饱和位点的构建、表征和催化应用方面已经取得重要进展, 本文将从配 位催化的视角对其进行总结与讨论. 配位催化的概念由Natta在讨论Ziegler-Natta催化剂的性质时提出, 已被广泛用于一系 列重要反应, 如加氢、氧化、羰基化、氢甲酰化和C-C键偶联中. 配位催化尽管表现出高活性、高选择性和反应机理清晰 等优点, 但通常的过渡金属配合物催化剂在分离与回收方面也存在明显缺陷. 沸石分子篮具有分子尺寸的规则孔道结构, 其骨架、孔道内与离子交换位均可以引入过渡金属离子构筑配位不饱和位点. 这一策略可以将配位化学与沸石化学的相 关概念结合起来, 并在多相催化反应过程中充分利用配位催化的优点.

本文首先介绍了沸石分子篮骨架内与骨架外配位不饱和位点不同构筑策略, 即离子交换-焙烧、扩散浸渍-焙烧、直接 水热合成、过渡金属配合物封装以及骨架脱铝补位修饰, 并对其特点进行了比较. 随后讨论了用于检测阳离子落位、存在 状态及其在沸石分子篮结构中动态变化的光谱技术, 包括振动光谱(傅里叶变换红外光谱、拉曼光谱)、电子光谱(紫外-可 见漫反射光谱、X射线光电子能谱)、共振波谱(固体核磁共振、电子自旋共振)以及 X射线吸收谱(X射线近边吸收、X射线 吸收精细结构). 最后一部分总结了含配位不饱和位点的沸石分子篮在代表性重要催化反应中的应用, 从氮氧化物转化、 $\mathrm{C}-\mathrm{H}$ 键活化(甲烷羟基化、苯羟基化、丙烷氧化脱氢)、烯烃功能化(聚合、环氧化)、环氧化物开环(水合、氨解)和羰基活化 (Baeyer-Villiger氧化重排、Meerwein-Ponndorf-Verley还原)等几类反应展开讨论. 对反应机理与构效关系的认识一直以来 是催化领域研究的挑战, 而对于含配位不饱和位点的沸石分子篮这样复杂的体系来说更是如此. 如果能够在沸石分子篮 结构内构筑均一且结构明确的孤立金属离子位点, 则可以将沸石分子篮骨架作为中心金属离子的配体, 从而将含配位不饱 和位点的沸石分子篮整体作为一类金属无机配合物, 有助于更好地理解催化反应过程与本质.
\end{abstract}

关键词: 配位不饱和位点; 沸石分子筛; 构筑; 表征; 催化应用

收稿日期: 2019-03-21. 接受日期: 2019-04-14. 出版日期: 2019-09-05.

*通讯联系人. 电话/传真: (022)23500341; 电子信箱: lild@nankai.edu.cn

基金来源：国家自然科学基金(21722303，21421001); 天津市自然科学基金(18JCJQJC47400, 18JCZDJC37400); 111项目(B12015, B18030).

本文的电子版全文由Elsevier出版社在ScienceDirect上出版(http://www.sciencedirect.com/science/journal/18722067). 